\title{
苯炔参与的去芳构化反应研究进展
}

\author{
间强 ${ }^{a}$ 范荣 ${ }^{b}$ 刘斌斌 $b$ 苏帅松 $b$ \\ 王 勃 $a$ 姚团利*, $a$ 谭嘉靖*, $b$ \\ $\left({ }^{a}\right.$ 陕西科技大学化学与化工学院 西安 710021) \\ $\left(^{b}\right.$ 北京化工大学化学学院 北京 100029)
}

\begin{abstract}
摘要 去芳构化反应是有机化学热点研究领域之一, 可从二维平面分子出发构筑高官能团化的三维立体分子. 近年来, 苯炔作为一类高活性中间体被有机化学家们广泛用于去芳构化反应研究中, 并取得了一系列创新成果. 从含氮芳杂环 同苯炔的去芳构化反应、苯炔与双烯体的 $[4+2]$ 环加成去芳构化反应以及苯炔以其它途径参与的去芳构化反应三个方 面，对机理进行系统性综述，并对该类反应未来的发展方向予以展望.
\end{abstract}

关键词 去芳构化; 苯炔; 含氮杂环; 多组分反应; 环加成反应

\section{Recent Progress in Aryne Participated Dearomatization Reactions}

\author{
Yan, Qiang ${ }^{a} \quad$ Fan, Rong $^{b} \quad$ Liu, Binbin $^{b} \quad$ Su, Shuaisong ${ }^{b}$ \\ Wang, $\mathrm{Bo}^{a} \quad$ Yao, Tuanli*,a Tan, Jiajing*,b \\ ( ${ }^{a}$ College of Chemistry and Chemical Engineering, Shaanxi University of Science \& Technology, Xi'an 710021) \\ ( ${ }^{b}$ College of Chemistry, Beijing University of Chemical Technology, Beijing 100029)
}

\begin{abstract}
Dearomatization reaction is one of the most popular research areas in organic chemistry. It could build highly functionalized three-dimensional molecules from readily available planar aromatic compounds. In recent years, arynes as reactive intermediates have been extensively investigated in dearomatization reactions, and a series of synthetic protocols have been reported. The mechanisms of the dearomatization reaction of azaarenes with arynes, the $[4+2]$ cycloaddition dearomatization reactions of arynes with dienes, and the dearomatization of arynes in other pathways are reviewed. The insights and outlooks regarding this rapid developing field are also provided.

Keywords dearomatization reactions; aryne; $N$-heteroaromatics; multicomponent reaction; cycloaddition reaction
\end{abstract}

去芳构化反应可为高官能团化的三维结构分子提 供高效合成路径. 2009 年, Lovering 等 ${ }^{[1]}$ 就提出 “Escape From Flatland” 概念, 芳香烃类化合物作为一类二维平 面分子, 若增加其饱和度可极大提高该类分子的结构复 杂性, 为合成含有三维、复杂脂肪碳(杂)环骨架的天然 产物、药物及功能分子提供高效路径. 去芳构化反应作 为一种重要的合成手段, 可通过打破芳香烃原有的平面 结构, 构筑具有三维立体结构的分子, 且使其高度官能 团化. 众所周知, 芳香族化合物的共轭 $\pi$ 体系结构稳定 性较高, 这使得去芳构化反应通常极具挑战. 传统的去 芳构化反应包括氧化去芳构化反应、亲核加成去芳构化 反应以及 $\sigma$ 重排去芳构化反应等 ${ }^{[2-4]}$. 近年来, 在有机化
学家们的不解努力下, 多类新型高效去芳构化反应被陆 续发现. 游书力课题组 ${ }^{[5]}$ 在 2012 年首次提出 “催化不对 称去芳构化 (Catalytic Asymmetric Dearomatization, CADA)” 概念, 并用此方法合成大量结构新颖的三维立 体分子骨架. 奕新军课题组 ${ }^{[6]}$ 近年来则利用过渡金属催 化的手段, 从廉价易得的溴代酚类化合物出发, 通过插 入炔烃参键, 经去芳构螺环化, 高效合成一系列结构多 样且含有季碳中心的螺环骨架化合物.

21 世纪以来, 有机化学家们利用苯炔化学高效实 现了大量芳香烃类分子的去芳构化反应. 相较于普通炔 烃，苯炔中间体环内参键具有极高张力，易被亲核试剂 进攻. 此外, 苯炔化学具有原料简单易得及条件温和等

* Corresponding authors. E-mail: yaotuanli@sust.edu.cn; tanjj@mail.buct.edu.cn Received September 3, 2020; revised September 29, 2020; published online October 27, 2020.

Project supported by the Fundamental Research Funds for the Central Universities (No. XK1802-6) at Beijing University of Chemical Technology. 北京化工大学中央高校基本科研业务费(No. XK1802-6)资助项目. 
优点, 故苯炔参与的去芳构化反应愈加受到广大有机化 学家们的高度关注. 尽管如此, 系统性论述苯炔参与的 去芳构化反应的综述尚未有报道. 本文将对苯炔参与的 去芳构化反应从以下三方面进行综述: (1)杂环芳烃具有 亲核性的杂原子进攻苯炔生成两性离子中间体后, 通过 分子内或分子间的反应实现去芳构化; (2)苯炔与双烯体 发生传统的[4+2]环加成反应, 使双烯体去芳构化后得 到桥环立体分子骨架; (3)苯炔以其它途径参与的去芳构 化反应.

\section{1 苯炔参与的含氮芳杂环的去芳构化反应}

含氮芳杂环由于其氮原子具有亲核孤对电子, 极易 与苯炔发生亲核加成反应. 苯炔与氮杂芳环反应所得到 的含氮两性离子中间体可再被预亲核试剂捕获, 发生分 子间或分子内的去芳构化反应. 此外, 预先活化的含氮 芳杂环可同苯炔发生偶极环加成反应，实现去芳构化. 本部分主要论述苯炔与含氮芳杂环发生的各类去芳构 化反应.

\section{1 基于含氮两性离子的去芳构化反应}

苯炔与含氮芳杂环形成的两性离子中间体可从预 亲核试剂中捕获质子, 进而通过活化的亲核试剂进攻氮 杂芳烃盐, 实现去芳构化. 2006 年, Cheng 课题组 ${ }^{[7]}$ 利用 苯炔与异喹啉(喹啉或吡啶)以及腈类化合物反应, 实现 1-乙腈基- $N$ - 苯基二氢异喹啉的高效合成(Scheme 1). 作 者提出, 苯炔首先与异咺啉 1 通过亲核加成形成含氮两 性离子中间体 2 , 随后捕获乙腈 $\alpha$ 位质子, 生成的乙腈 负离子进攻异喹啉盐便得到目标产物 4 . 溶剂乙腈分子 在此反应中作为质子供体, 促进氮杂芳烃的去芳构化反 应进行.

基于上述工作, 该课题组 ${ }^{[8]}$ 又报道苯炔、喹啉(异喹 啉或吡啶)和端炔的三组分去芳构化反应(Scheme 2,a).
该反应经由相同路径形成的两性离子中间体 $\mathbf{6}$ 可算取炔 氢, 端炔负离子再与喹啉盐发生亲核加成反应即可实现 去芳构化. 该反应底物适用范围较广, 且反应条件温和. 此外，上述两性离子中间体也可算取酮的 $\alpha$-氢，实现类 似的三组分去芳构化反应(Scheme 2，b).1,2-二氢-2-吡 啶炔烃产物 9 可再同氮苯基马来酰亚胺 10 发生 [4+2] 环加成反应(Scheme 2, c), 所构筑的杂环骨架 11 广泛存 在于天然产物中 ${ }^{[9]}$, 具有潜在应用前景.

2016 年, 何林课题组 ${ }^{[10]}$ 利用相似策略, 实现苯炔、 喹啉(或异喹啉)同亚磷酸二酯的三组分去芳构化反应 (Scheme 3). 同上, 苯炔与喹啉反应得到的两性离子中 间体 $\mathbf{6}$, 可从亚磷酸二酯中篗取质子. 随后, 亚磷酸二 酯基阴离子进攻活化的喹啉盐完成去芳构化反应. 该反 应将去芳构化与磷酰化反应有效结合, 可构建结构多样 的 $N$-苯基-2-亚磷酸二酯基二氢喹啉类化合物. 但该反 应含磷底物仅适用于亚磷酸二烷基酯, 对于亚磷酸二苯 酯, 则难以捕获两性离子中间体 $\mathbf{6}$ 完成此类反应.

2018 年, 谭嘉靖课题组 ${ }^{[1]}$ 利用氯仿作为质子源和 亲核试剂, 高效实现苯炔促进喹啉和异喹啉的去芳构化 反应(Scheme 4). 该反应使用氯仿和乙腈的混合溶剂体 系. 和上述 Cheng 课题组 ${ }^{[7]}$ 的报道不同，作者通过对反 应条件的精准调控, 使得氯仿作为此反应的唯一质子供 体，而且未观测到乙腈参与的三组分反应. 值得一提的 是, 含気化合物在药物化学中扮演着重要角色, 作者还 利用廉价易得的氞代氯仿作为氞源，以最高 $95 \%$ 的氞代 率实现一系列相应氝代去芳构化产物 15 的高效合成. 该反应底物适用范围广, 产率较高, 且可用于克级规模 的制备反应.

通过引入 “ $\mathrm{X}=\mathrm{Y}$ ” 型底物, 也可利用该类三组分反 应可实现芳环的邻位双官能团化. 2013 年, Biju 课题 组 ${ }^{[12]}$ 发展一类苯炔、异喹啉(喹啉)和靛红的三组分去芳
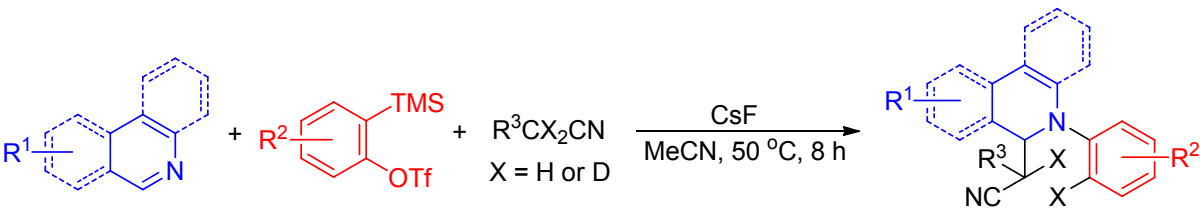

18 examples $45 \% \sim 89 \%$ yield

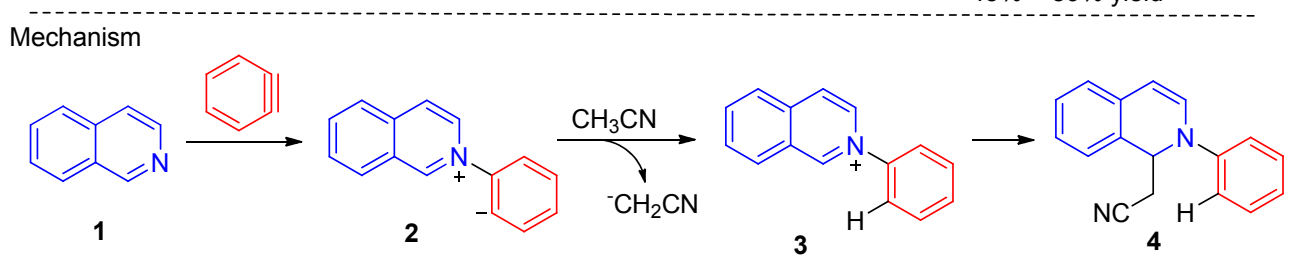

图式 1 苯炔、乙腈与异喹啉的三组分去芳构化反应

Scheme 1 Three-component dearomatization reaction of arynes, acetonitriles and isoquinolines 


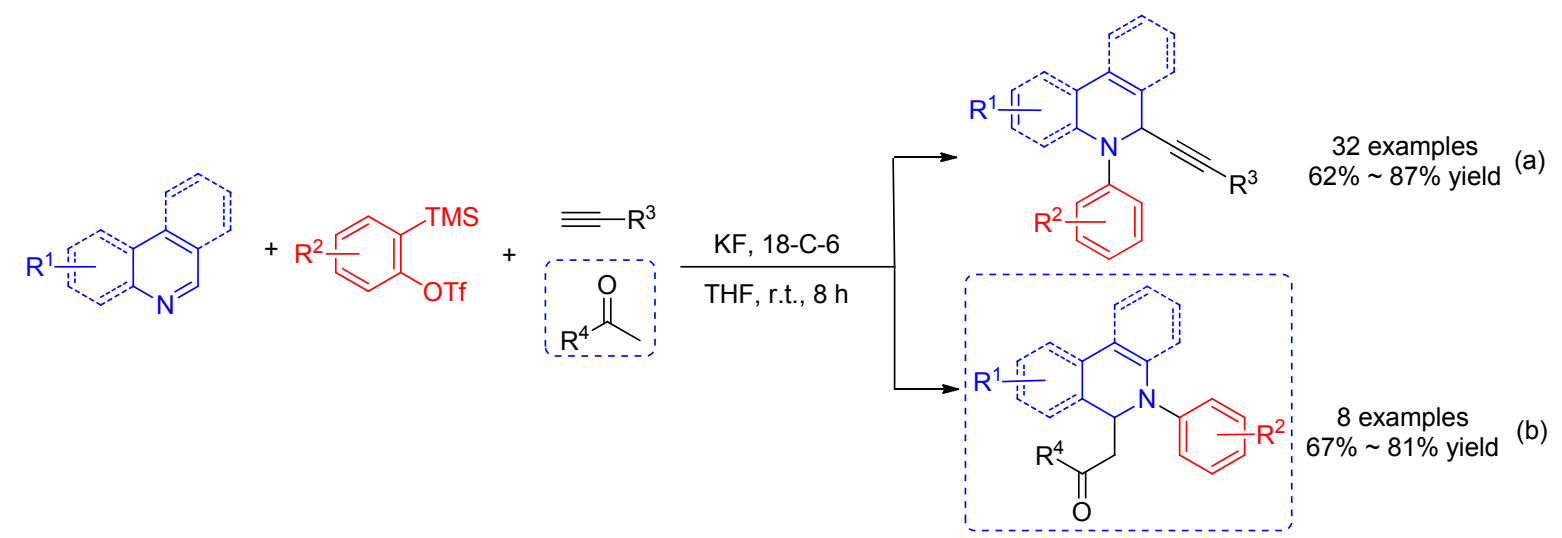

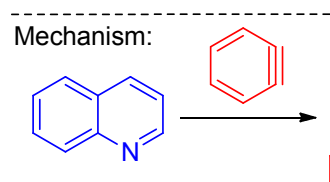

5<smiles></smiles><smiles>C#CC(c1ccccc1)(c1ccccc1)c1ccccc1</smiles>
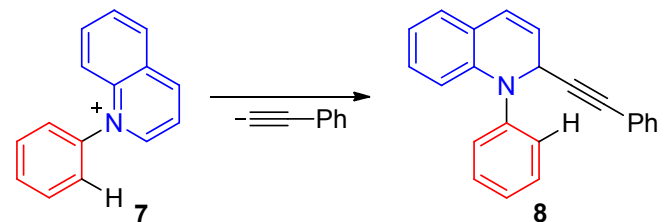

8

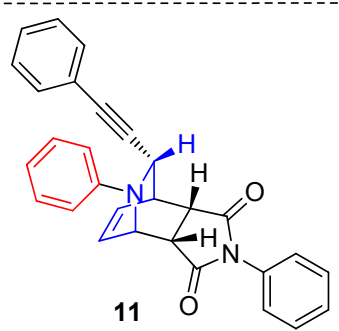

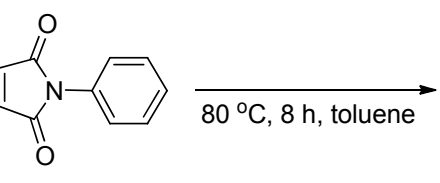

10

11

图式 2 苯炔、端炔(酮)和喹啉的三组分去芳构化反应

Scheme 2 Three-component dearomatization reaction of arynes, terminal alkynes (ketones) and quinolines

$$
\text { (18-C-6 }
$$

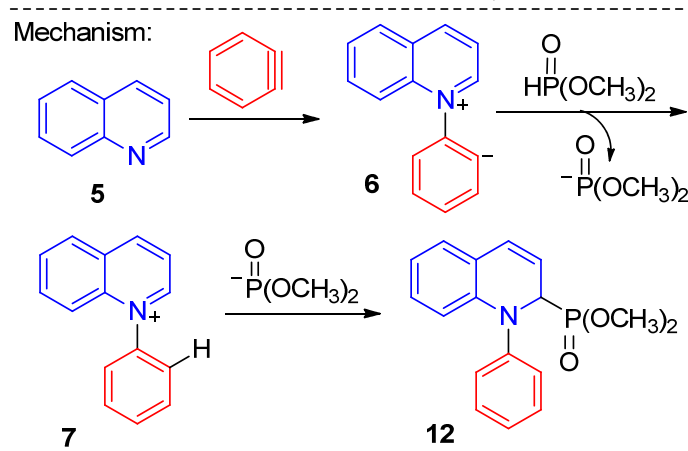

图式 3 苯炔引发的亚磷酸二酯与(异)喹啉的三组分去芳构化 反应

Scheme 3 Aryne induced three-component dearomatization reaction of dialkylphosphites and (iso)quinolines
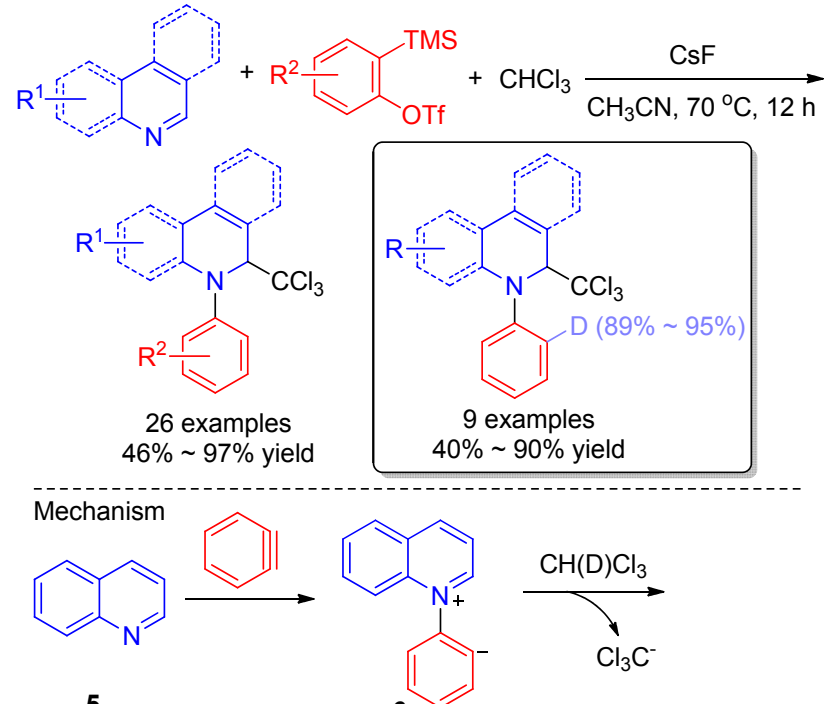

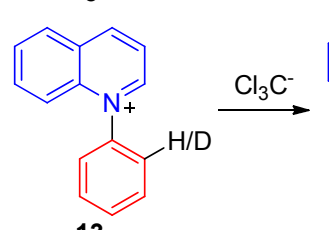

13
6

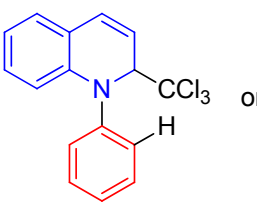

14

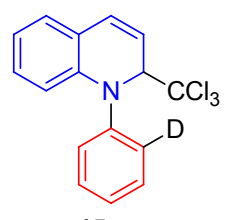

15
图式 4 苯炔引发的(异)喹啉与氯仿的三组分去芳构化反应 Scheme 4 Aryne induced three-component dearomatization reaction of (iso)quinolines and chloroform 
构化反应(Scheme 5). 反应过程中使用不同的芳香含氮 杂环底物(异喹啉或喹啉)时, 可得到两类 3 位取代的吲 哚酮产物. 当底物为异喹啉时, 其首先进攻苯炔形成含 氮两性离子中间体 2 , 随后对羰基加成, 伴随生成的氧 负离子继而进攻异喹啉盐即得到目标产物 17 , 该反应 收率与非对映异构体的比值 $(d r)$ 最高可达 $90 \%$ 和 $20 ： 1$.

同年, Biju 课题组 ${ }^{[13]}$ 利用上述策略, 以苯炔、喹啉
(异喹啉)和醛类化合物为原料, 发展了一类可用于合成 苯并噁嗪的去芳构化反应(Scheme 6, a). 作者提出反应 机理如下：苯炔与喹啉生成两性离子中间体 6, 随后与 醛类化合物通过加成反应生成中间体 18 , 氧负离子再 进攻喹啉盐生成环化产物 19. 此外, 1,4-苯醌、二苯甲酮 和 $\alpha$-酮酯也可用作活化的羰基源，体现出相同反应活性 (Scheme 6, b).<smiles>[R1]c1ccc2cnc3ccccc3c2c1</smiles><smiles></smiles>

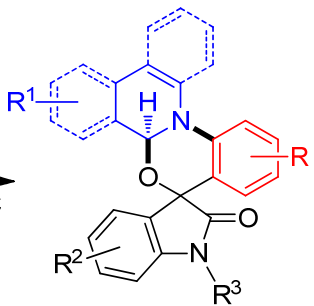

$\mathrm{R}^{3}$

15 examples $60 \% \sim 90 \%$ yield $20: 1 d r$

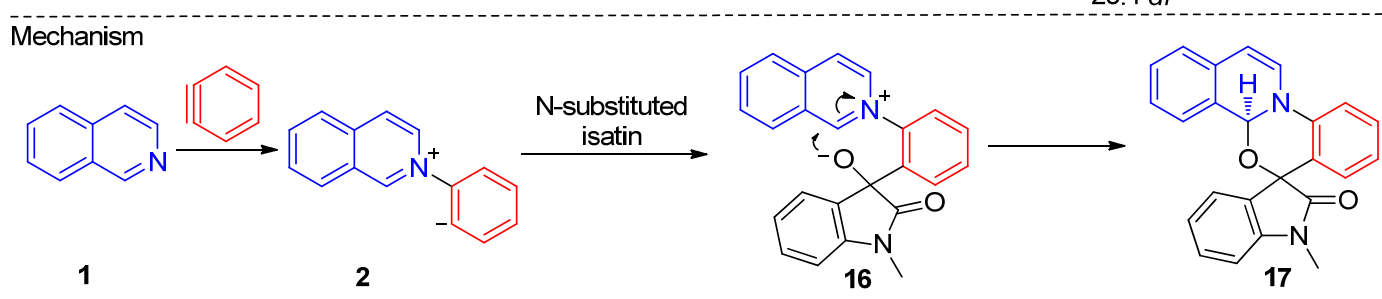

图式 5 苯炔、靛红与喹啉(吡啶)的三组分反应

Scheme 5 Three-component reaction of arynes, isatins and quinolines (pyridines)

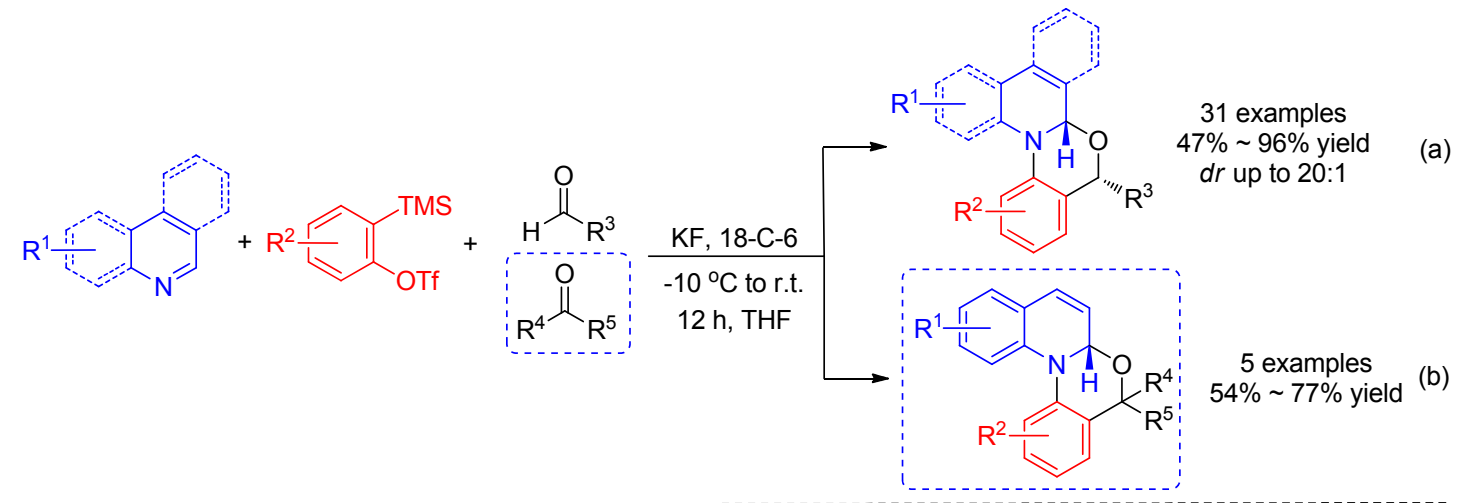

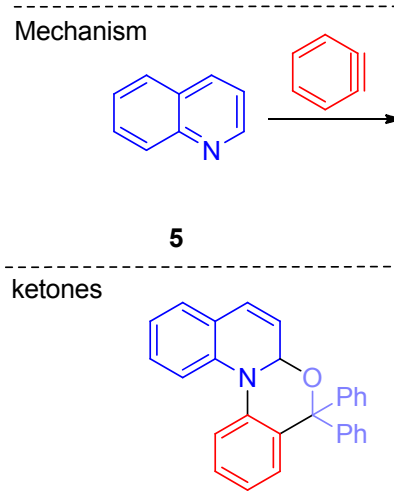

$20,54 \%$
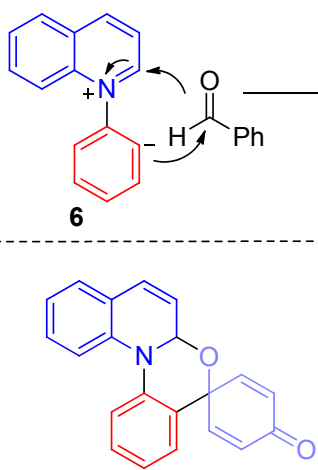

21, $59 \%$

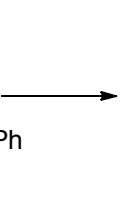<smiles>CCC</smiles>

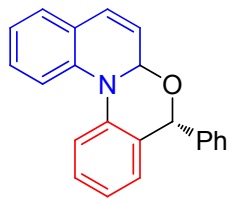

19

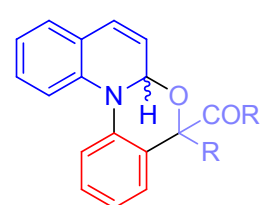

$\mathrm{R}=\mathrm{Ph}, \mathbf{2 2}, 63 \%,(10: 1)$

$\mathrm{R}=$ thienyl, 23, 56\%, (1:1)

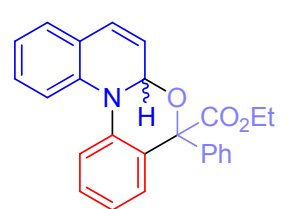

24, $77 \%,(>20: 1)$

图式 6 苯炔、醛(酮)与喹啉的三组分去芳构化反应

Scheme 6 Three-component dearomatization reaction of arynes, aldehydes(ketones) and quinolines 
胡立宏课题组 ${ }^{[14]}$ 也利用相同思路发展一类噁嗪类 化合物的高效合成方法(Scheme 7). 同上述 Biju 课题 组 ${ }^{[13]}$ 的报道相比, 作者对产物立体化学现象进行详细 论证. 其利用奥弗豪塞尔核效应(NOE)实验对分离得到 的 cis 与 trans 两种构型产物结构进行鉴别, 进一步阐明 该反应过程中的立体选择性问题. 此外, 当使用 3-甲氧 基苯炔(27)时, 由于甲氧基的电子效应及空间位阻的影 响, 氮杂芳烃氮原子优先进攻 1-甲氧基苯炔中间体 28 的 3 号位, 使其形成两性离子中间体 29, 进而与醛发生 加成得到 cis 型产物 $\mathbf{3 0}$.

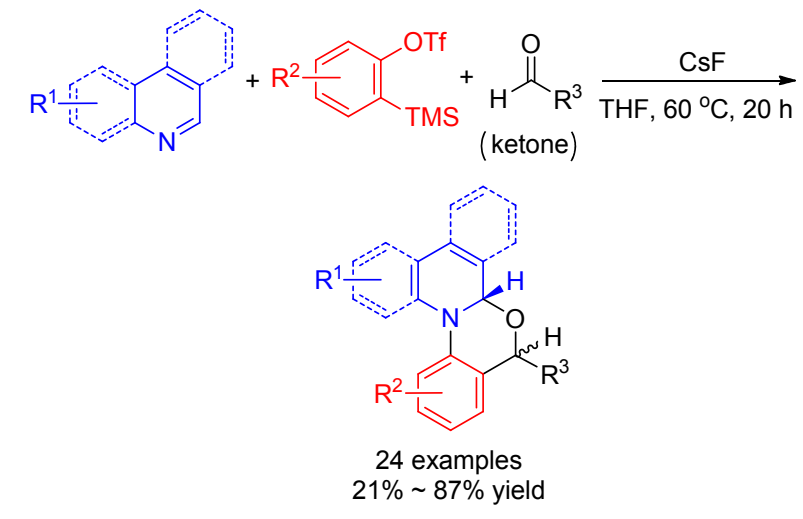

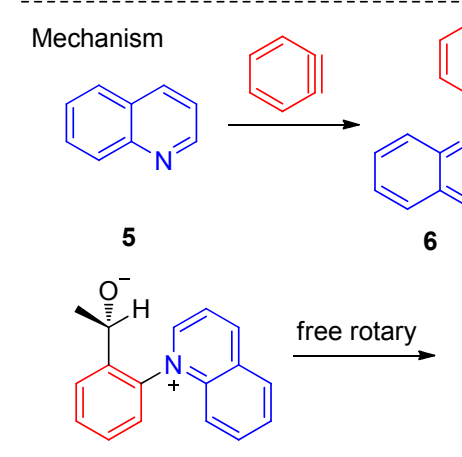

25

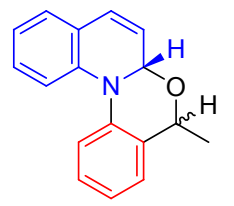

26

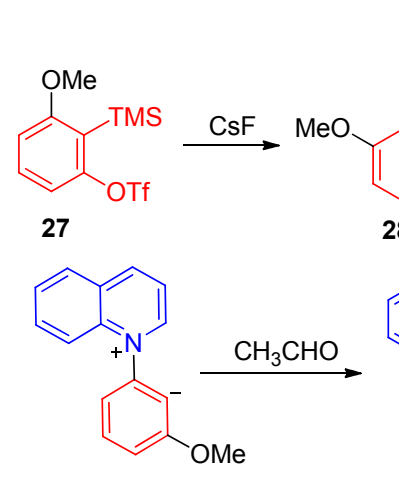

29

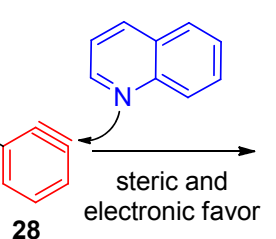

28

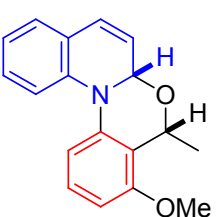

图式 7 苯炔引发的醛(酮)与喹啉的三组分去芳构化反应 Scheme 7 Aryne induced dearomatization reaction of aldehydes (ketones) and quinolines

上述由亲核加成引发的缺电子氮杂芳环的去芳构 化反应，可同苯炔的插入反应进行整合，“一石二鸟”
实现芳环的邻位双官能团化. 2018 年，田仕凯课题组与 余志祥课题组 ${ }^{[15]}$ 共同报道苯炔、四氯化碳同吡啶的三组 分去芳构化反应(Scheme 8). 密度泛函理论(DFT)计算 显示反应机理为: 首先苯炔与氮杂芳环作用生成两性离 子中间体 32, 32 再与四氯化碳上的氯原子形成瞬时过渡 态 33，随后三氯甲基负离子亲核进攻中间体 34, 生成 1-(2-氯苯基)-2-三氯甲基-1,2-二氢吡啶(35). 此外，喹 啉、异喹啉、菲啶以及酞嗪均可作为氮杂芳烃组分实现 上述反应.

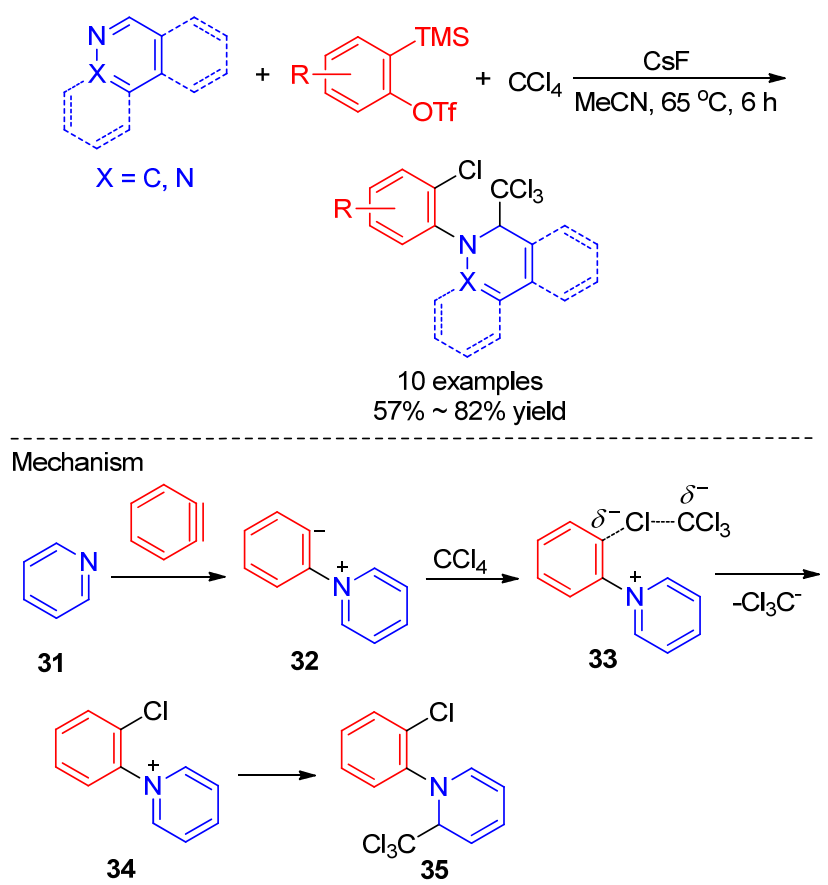

图式 8 苯炔、四氯化碳与氮杂芳烃的三组分去芳构化反应 Scheme 8 Three-component dearomatization reaction of arynes, carbon tetrachloride and azaarenes

利用合理的底物设计, 氮杂芳烃也可同苯炔发生两 组分去芳构化反应. 2001 年, Cheng 课题组 ${ }^{[16]}$ 利用亚硝 酸异戊酯引发邻氨基苯甲酸(36)生成苯炔中间体. 其与 苯甲酸-2-吡啶酯通过亲核加成反应生成两性离子中间 体 37, 苯基碳负离子分子内进攻羰基碳原子, 通过加成 消除过程最终生成目标产物 1-(2-酰基苯基)-2-吡啶酮 (38) (Scheme 9), 实现去芳构化. 该反应以吡啶分子上 的酯基作为亲电位点，通过分子内反应捕获上述含氮两 性离子, 故无需第三组分即可实现吡啶环的去芳构化.

2012 年, Larock 课题组 ${ }^{[17]}$ 则利用 2-丙烯酸酯基吡啶 或 2-亚胺基吡啶和苯炔为反应原料, 通过去芳构化反应 合成吡啶 $[1,2-a]$ 吲哚产物 41 或 45 . 作者起初利用单酯 基取代的 2-丙烯酸酯基吡啶与苯炔反应并未得到目标 产物，但当使用二酯基取代的底物时，由于 Michael 受 体的亲电性增强, 可推动目标反应顺利进行(Scheme 10, 


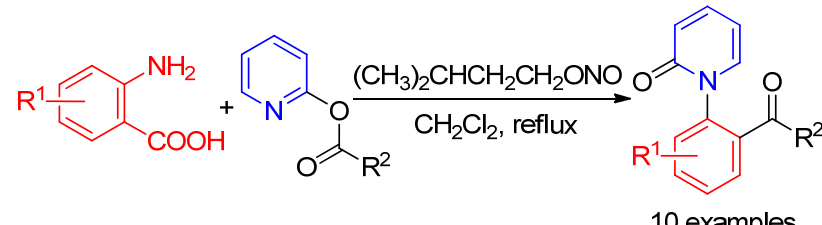

$48 \% \sim 74 \%$ yield

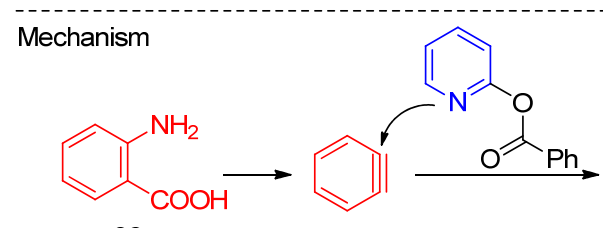

36<smiles></smiles>

图式 9 苯炔与 2-吡啶羧酸酯的去芳构化反应

Scheme 9 Dearomatization reaction of arynes and pyridin-2-yl carboxylates

a), 机理研究表明 2-丙烯酸酯基吡啶与苯炔形成的两性 离子中间体 40 通过共轭加成环化, 最终完成去芳构化. 该合成方法对不同酯基取代的底物具有较好的兼容性. 当使用 2-亚胺基吡啶时, 反应机理类似. 去芳构化后产 物 44 中的氨基可再同另一分子苯炔反应, 最终得到氮 芳基化产物 45 (Scheme 10, b).

2017 年, 程斌课题组 ${ }^{[18]}$ 报道苯炔同 2-酰胺基吡啶 的去芳构化反应(Scheme 11). 2-酰胺基吡啶与苯炔形成 的两性离子中间体 47 篗取氨基上的活泼氢, 双键异构 从而促使吡啶发生去芳构化得到目标产物 48. 作者通 过对原料比例和温度的调控, 避免了苯炔直接插入酰胺 碳一氮键的副产物的生成. 此外, 增大苯炔、氟化钾以及 18-冠醚-6 的用量, 可进一步实现上述去芳构化和 $[4+2]$ 环加成的串联反应，一步构筑桥环产物 49.

2012 年, Hoye 课题组 ${ }^{[19]}$ 通过分子内六氢狄尔斯-阿 尔德反应(Hexadehydro Diels-Alder, HDDA)反应，可从 链状三炔分子环化生成苯炔中间体. 反应条件常为中 性, 所生成芳炔的结构具有多样性, 可对常用的 Kobayashi 苯炔前体形成有效互补. 2019 年, 该课题组 [20]利用 HDDA 方法合成苯炔, 并由此引发一系列新颖 的六元氮杂芳烃的去芳构化反应(Scheme 12). 在无第 三组分反应物参与时, 底物三炔与氮杂芳烃加热形成两 性离子中间体，该中间体在热力学控制下可发生分子内 亲核加成反应，生成四元环加成产物(Scheme 12,a). 若 向体系中加入第三组分反应物后, 两性离子中间体也可 通过类似机理发生三组分去芳构化反应(Schemes 12, b, (a)

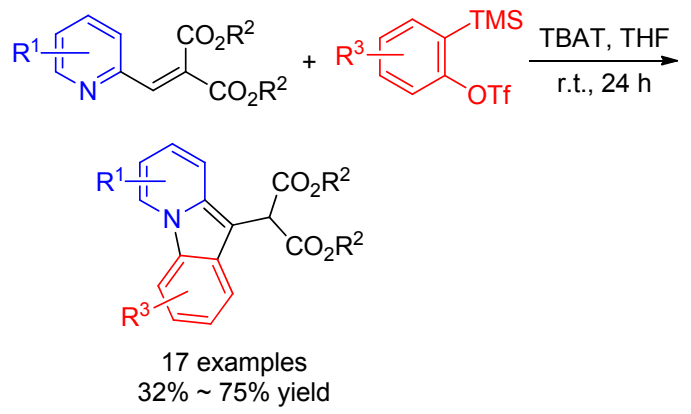

Mechanism
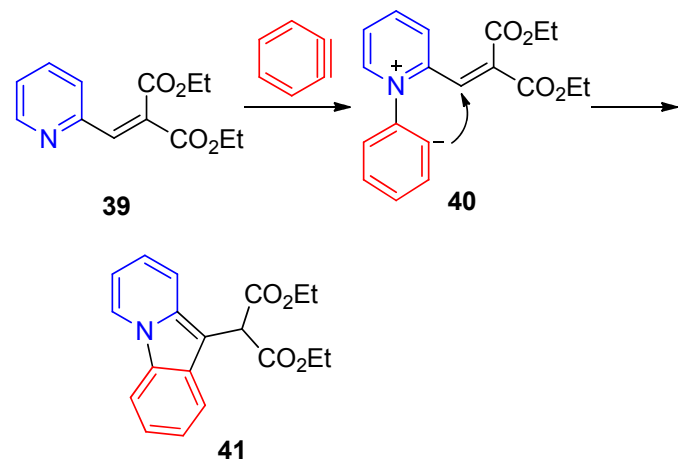

(b)

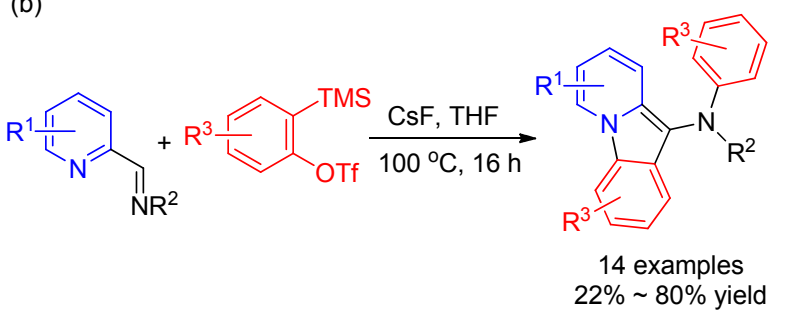

Mechanism

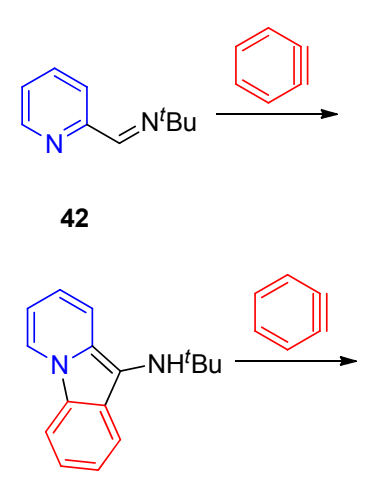

44

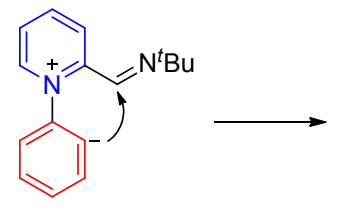

43

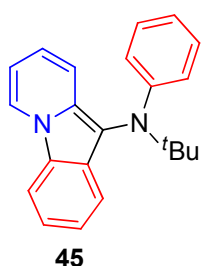

图式 10 苯炔与 2-丙烯酸酯基吡啶以及 2-亚胺基吡啶的去芳 构化反应

Scheme 10 Dearomatization reaction of arynes with 2-acrylate pyridines or 2-iminopyridines

c). 该反应氮杂芳烃底物较广, 除常见的吡啶、喹啉与异 喹啉外，菲啶、酞嗪和嘧啶等均可参与该类反应. 


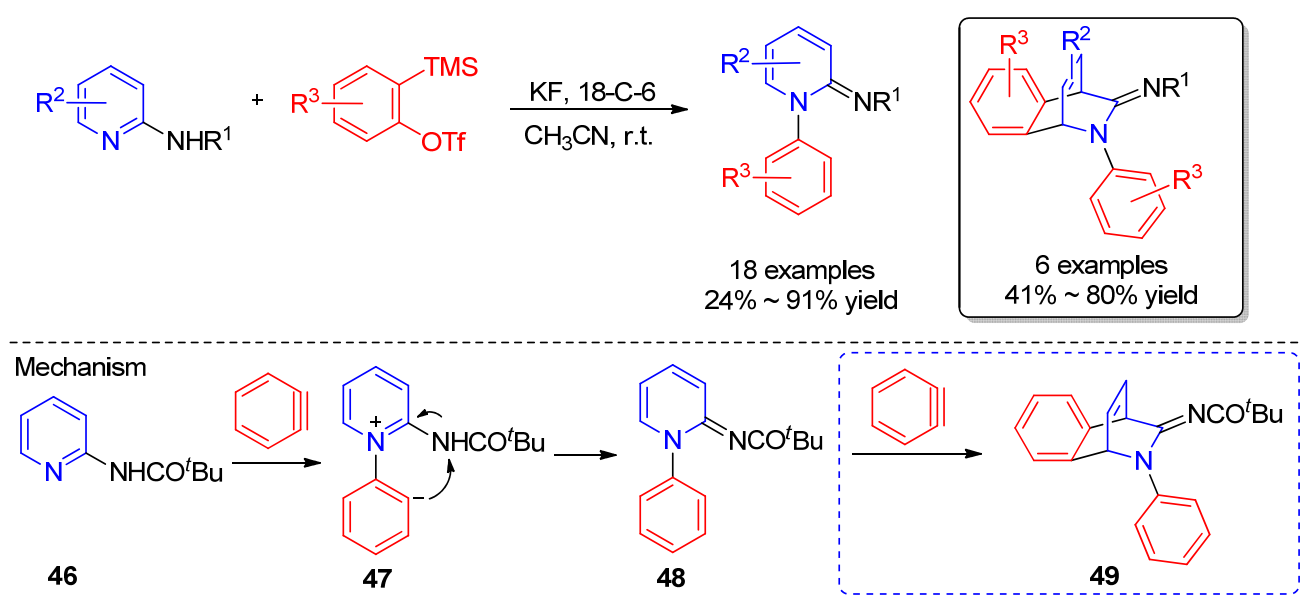

图式 11 苯炔与 2-酰胺基吡啶的去芳构化反应

Scheme 11 Dearomatization reaction of arynes and 2-amidylpyridines

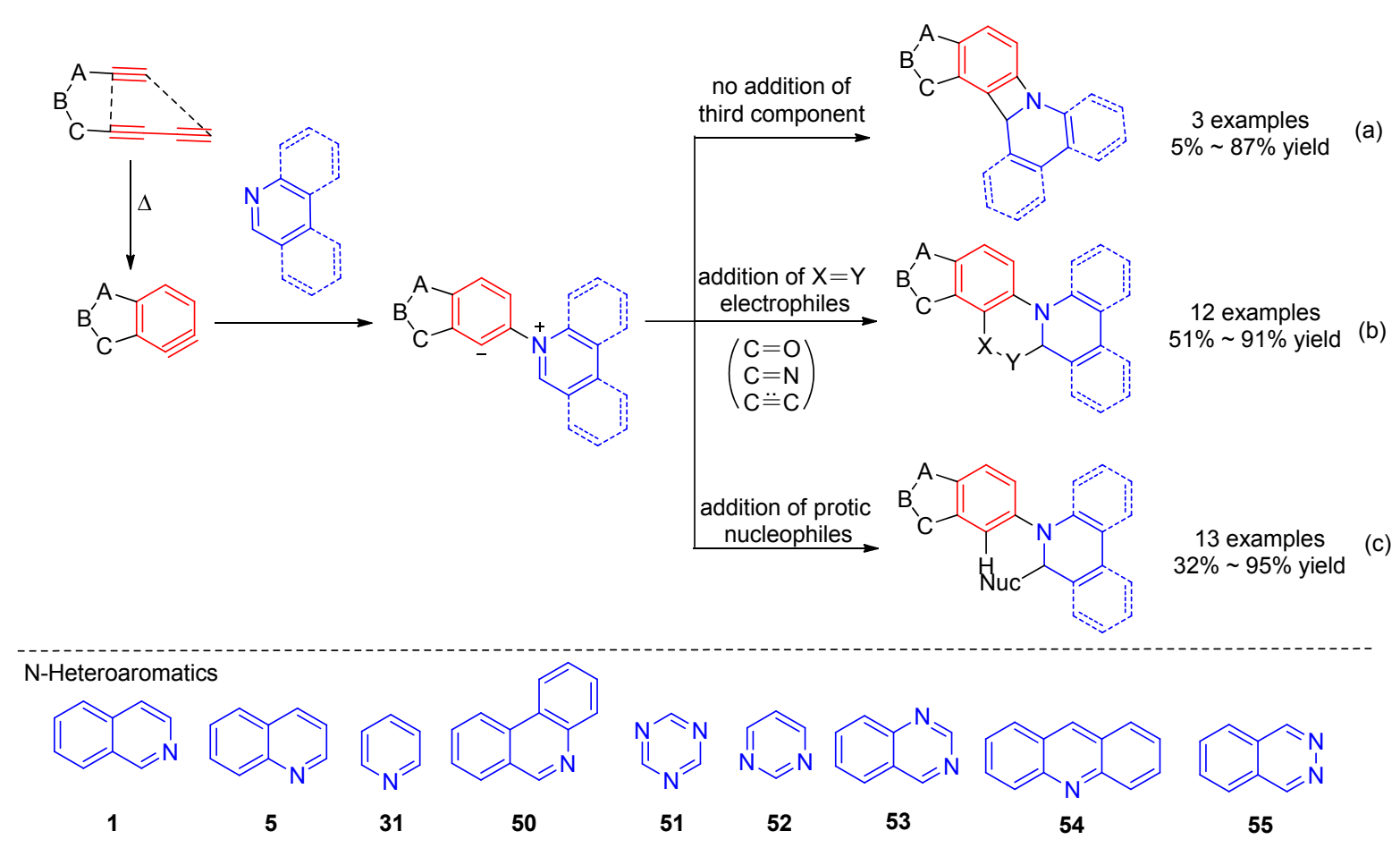

图式 12 HDDA 苯炔与氮杂芳烃的去芳构化反应

Scheme 12 Dearomatization reaction of HDDA arynes and azaarenes

\section{2 活化氮杂芳烃的[3+2]环化去芳构化反应}

含氮芳杂环被预先活化后作为偶极子可同苯炔发 生[3+2]环化反应实现去芳构化. 早在 1980 年, Masumura 课题组 ${ }^{[21]}$ 用预先制备的 $N$-苯甲酰胺基吡啶盐与苯 炔反应(Scheme 13,a), 通过[3+2]环加成, 实现了吡啶 环的去芳构化. 2011 年, 史峰课题组 ${ }^{[22]}$ 利用 Kobayashi 苯炔前体, 也完成了类似的对甲苯磺酰胺基吡啶盐与苯 炔的 $[3+2]$ 环加成去芳构化反应(Scheme 13, b). 作者提 出如下反应机理: 对甲苯磺酰胺基吡啶盐与苯炔反应得 到环加成产物 57 , 其在氟离子作用下脱去对甲苯磺酰
胺基负离子, 进而得到目标产物 $\mathbf{5 8}$. 当使用酰胺基喹啉 盐或异喹啉盐时，相同条件下依然可利用该反应得到相 应目标产物.

2008 年, 黄宪课题组 ${ }^{[23]}$ 报道一类吡啶(异喹啉)、 $\alpha$ 溴代羰基化合物和苯炔的 [3+2]环化去芳构化反应 (Scheme 14, a). 吡啶(31) 首先同 $\alpha$-溴代羰基化合物形成 吡啶盐 59, 随后在碱的作用下去质子化形成叶立德中 间体 60. 进而和苯炔发生 $[3+2]$ 环加成反应, 得到去芳 构化产物 61. 作者通过对反应条件的合理优化，成功避 免吡啶氮原子直接进攻苯炔的副反应. 同年, 张玉红课 题组 ${ }^{[24]}$ 也报道相似的三组分反应，在乙腈作溶剂的条 
(a)

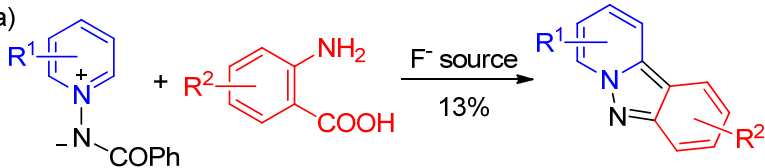

(b)

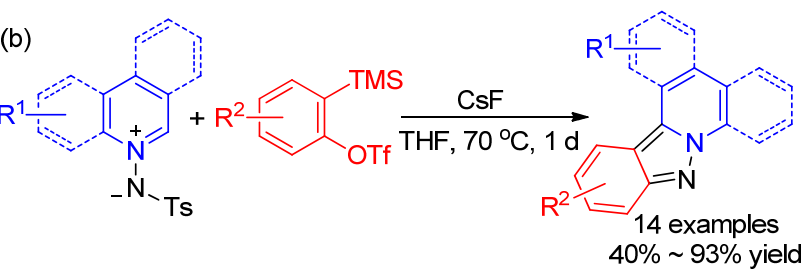

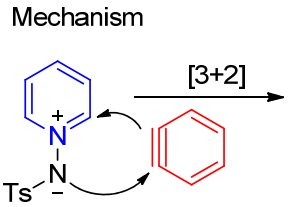

56

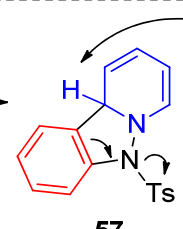

57

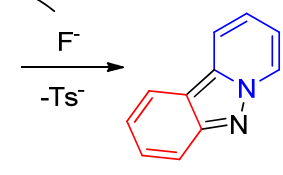

58

图式 13 苯炔与 $N$-对甲苯磺酰胺基吡啶盐的 [3+2]环加成反 应

Scheme $13[3+2]$ cycloaddition reaction of arynes with $N$ tosylpyridinium amides

(a)

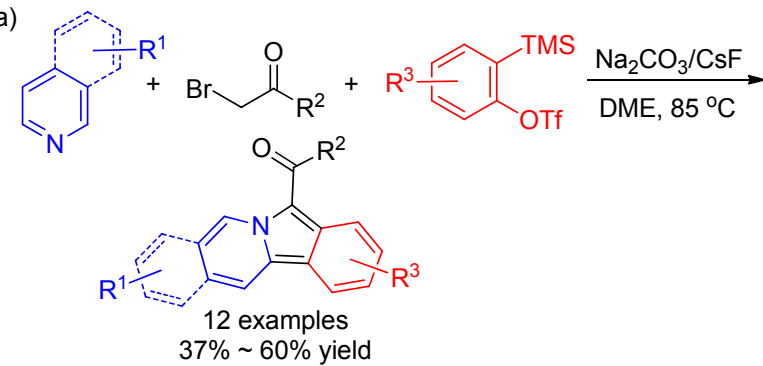

(b)<smiles>[R4][R1]1ccc2cc3c4cc([R])ccc4c(C(=O)c4ccc([R])cc4)n3cc2c1</smiles><smiles>Cc1cccnc1</smiles>

31<smiles>O=C(c1ccccc1)c1c2ccccc2c2ccccn12</smiles>

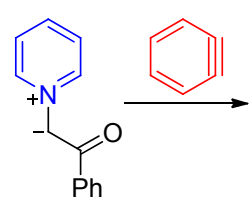

60

图式 14 苯炔与吡啶叶立德的 $[3+2]$ 环加成反应

Scheme $14[3+2]$ cycloaddition reaction of arynes with pyridine ylides

件下底物结构更具多样性(Scheme 14, b).

2013 年, Okuma 课题组 ${ }^{[25]}$ 报道喹啉氮氧化物与苯炔 的去芳构化反应. 反应机理如下：氮氧化物 62 首先同苯 炔发生 1,3-偶极环加成反应生成异噁唑啉环中间体 63 . 一方面, 63 可经过质子迁移生成副产物 2-羟基苯基-喹 啉 64; 另一方面，可再同另一分子苯炔发生氮一氧键间 的插入，生成去芳构化产物二苯并 $[1,4]$-氧氮杂环庚烷 [4,5-a]喹啉 65 (Scheme 15).
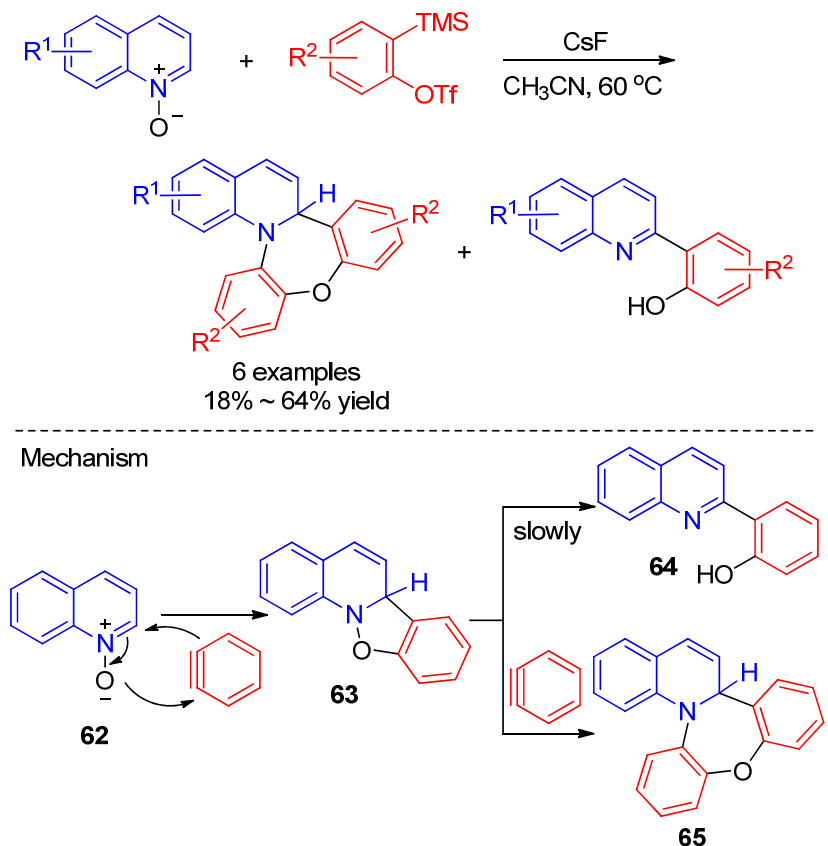

图式 15 苯炔与喹啉氮氧化物的 $[3+2]$ 环加成反应

Scheme $15[3+2]$ cycloaddition reaction of arynes with quinoline $N$-oxides

\section{2 苯炔同双烯体的[4+2]环加成去芳构化反应}

苯炔参与的 $[4+2]$ 环加成反应是一种构建苯并碳环 和杂环的高效策略，也可作为验证苯炔中间体生成的工 具. 由于苯炔拥有低能级的最低空分子轨道(LUMO), 其作为高活性亲双烯体可与多种双烯体(呋喃和吡咯等) 发生环加成反应. 20 世纪 50 年代, Wittig ${ }^{[26]}$ 利用苯炔与 呋喃通过[4+2]环加成反应得到桥环产物，成功实现呋 喃的去芳构化. 随后, Roos 等课题组 ${ }^{[27]}$ 相继报道了苯炔 与呋喃、吡咯、噻吩、苯并呋喃、苯并吡咯、葱等发生 的 [4+2]环加成反应(Scheme 16), 实现双烯体的去芳构 化. 此外，通过与其它分子间反应相结合的方式，可将 苯炔的 $[4+2]$ 环加成去芳构化反应用于串联合成，构建 结构更为复杂的三维分子. 由 Kobayashi 前体 ${ }^{[28]}$ 原位生 成的苯炔在氟离子引发条件下，也可被化学家们作为亲 双烯体用于 $[4+2]$ 环加成反应构筑上述桥环产物，此处 不再赘述. 本部分主要从不同条件引发下的苯炔 $[4+2]$ 环加成反应与天然产物全合成中的应用两方面进行简 
述.

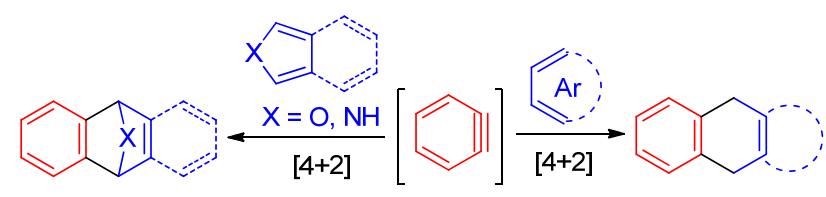

图式 16 苯炔与双烯体的 $[4+2]$ 环加成反应 Scheme $16 \quad[4+2]$ cycloaddition reaction of arynes and dienes

\section{1 不同引发条件下的苯炔 $[4+2]$ 环加成反应}

苯炔作为亲双烯体可与环状二烯结构发生 $[4+2]$ 环 加成反应, 进而实现去芳构化. 2002 年, Lee 课题组 ${ }^{[29]}$ 以 苯并噁二硅氧烷(66)为原料, 在氟离子引发下原位生成 苯炔(Scheme 17, a), 令其与呋喃发生 [4+2]环加成反应, 得到氧桥环去芳构化产物 67, 进一步脱氧可得到扩环 产物 68. 2004 年, 该课题组 ${ }^{[30]}$ 又用此方法生成环张力较 大的 1,4-苯二炔(Scheme 17, b), 其可同呋喃发生两次 $[4+2]$ 环加成反应得到双桥环去芳构化产物 70. 随后, 该课题组 ${ }^{[11]}$ 又利用带有噁二硅氧烷基的异苯并呋喃 72 与苯炔发生 $[4+2]$ 环加成反应, 制备噁二硅氧烷基葱 $\mathbf{7 4}$ (Scheme 17, c).

(a)

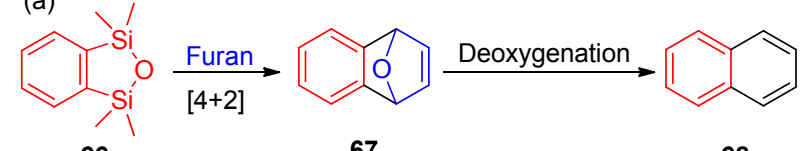

66

67

68

(b)<smiles>C[Si](C)(C)c1cc2c(cc1[Si](C)(C)C)[Si](C)(C)O[Si]2(C)C</smiles>

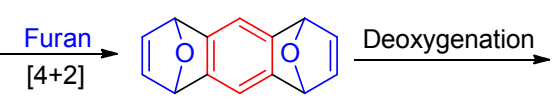

70

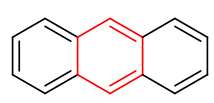

71

(c)

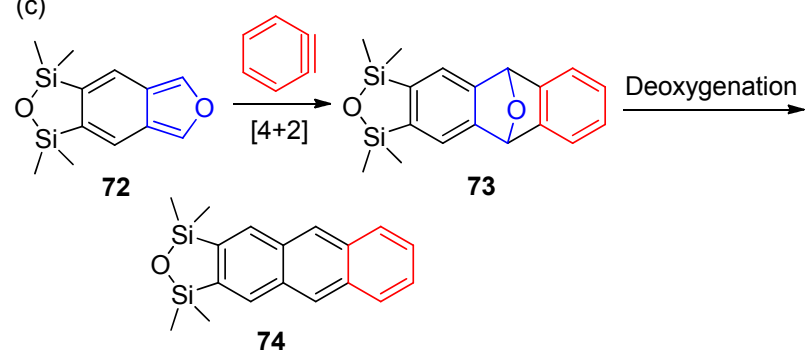

图式 17 苯并噁二硅氧烷生成的苯炔与呋喃的 [4+2]环加成 反应

Scheme $17[4+2]$ cycloaddition reactions of furans with arynes generated from benzooxadisiloles

基于上述工作, 2010 年, 该课题组 ${ }^{[32]}$ 又利用 $[4+2]$ 环加成反应去芳构化策略构筑了复杂的苯并二氢葱环
产物(Scheme 18). 作者提出如下反应机理：苯并二(噁 二硅氧)烷(75)与二乙酰基碘苯生成中间体 76, 76 在氟离 子引发下生成苯炔中间体 77 , 进而和葱发生 $[4+2]$ 环加 成反应生成去芳构化产物噁二硅氧烷基苯并二氢葱 78 . 利用该类 $[4+2]$ 环加成反应，可构筑一系列苯并二氢葱 环产物 $80 \sim 86$.

2011 年, Akai 课题组 ${ }^{[33]}$ 以邻-(三甲基硅烷基)苯酚 (87)为苯炔前体，通过全氟丁基磺酰氟(NfF)活化酚羟 基, 进而产生苯炔, 令其与呋喃反应得到去芳构化产物 88 (Scheme 19, a). 最近, 该课题组 ${ }^{[34]}$ 又以邻羟基苯硼 酸为苯炔前体, 在丙二醇与 $\mathrm{NfF}$ 作用下完成该类去芳构 化反应. 2013 年, Hosoya 课题组 ${ }^{[35]}$ 用邻三氟甲磺酸酯基 苯硼酸频哪醇酯 89 作为苯炔前体, 使其与呋喃(或吡咯) 在正丁基锂作为碱的条件下，发生[4+2]环加成反应， 得到了去芳构化产物 90 (Scheme 19, b). 2018 年, 王秋 课题组 ${ }^{[36]}$ 则用简单易得的芳基三氟甲磺酸酯 91, 在 $\mathrm{LiZnEt}_{2}$ (TMP)作用下, 直接将芳基三氟甲磺酸酯邻位去 质子化后, 原位消除三氟甲磺酸酯基(OTf)产生苯炔, 其可与异苯并呋喃通过环加成反应实现去芳构化 (Scheme 19, c).

2018 年, Prévost 课题组 ${ }^{[37]}$ 发展了一类苯炔与呋喃 的分子内 $[4+2]$ 环加成去芳构化反应(Scheme 20). 底物 93 在正丁基锂作用下原位生成苯炔，再与呋喃反应，在 酸促进下氧桥链断裂生成䒬酚 94 . 产物 94 再经氯铬酸 吡啶盐氧化成酸酐后，与 $N, N$-二甲基乙二胺反应可得到 生物活性小分子骨架菜酰亚胺 $\mathbf{9 5}$.

红苂烯 100 具有多个大 $\pi$ 键共轭体系, 被广泛应用 于光电材料领域, 此类分子较大的共轭系统可改善其发 光性能. Hamura 课题组 ${ }^{[38}$ 利用 2,3-二溴-1,4-苯乙炔基芸 (96)在强碱作用下生成相应芳炔中间体, 再与 1,3 -二苯 乙炔基异苯并呋喃(97)发生 $[4+2]$ 环加成反应, 生成去 芳构化产物 98, 随后在酸性条件下氧桥环断裂得到 5,6,11,12-四苯乙炔基并四苯(99) (Scheme 21). 经过光学 性能测试, 此类分子的发光性能要远高于红荧烯. 产物 99 因其具有多个参键，易通过分子内周环反应进一步 构建稠环产物 101 和 102.

2020 年, Suzuki 课题组 ${ }^{[39]}$ 实现分子内苯炔与苯酚的 [4+2]环加成去芳构化反应(Scheme 22). 作者利用 2-溴 苯基三氟甲烷磺酸盐 103 在三苯基锂化镁作用下原位生 成苯㶧, 再与分子内的苯环发生 $[4+2]$ 环加成反应, 可 构筑一系列苯环的去芳构化产物 105. 作者通过对反应 条件的调控, 成功避免了苯炔与苯酚发生直接偶联产生 副产物. 此外, 正丁基锂作为苯炔生成的引发剂也可完 成该类反应，但产率较低. 作者认为是由于三苯基锂化 镁产生的副产物二苯基镁, 可促使硅一氧键加速断裂. 

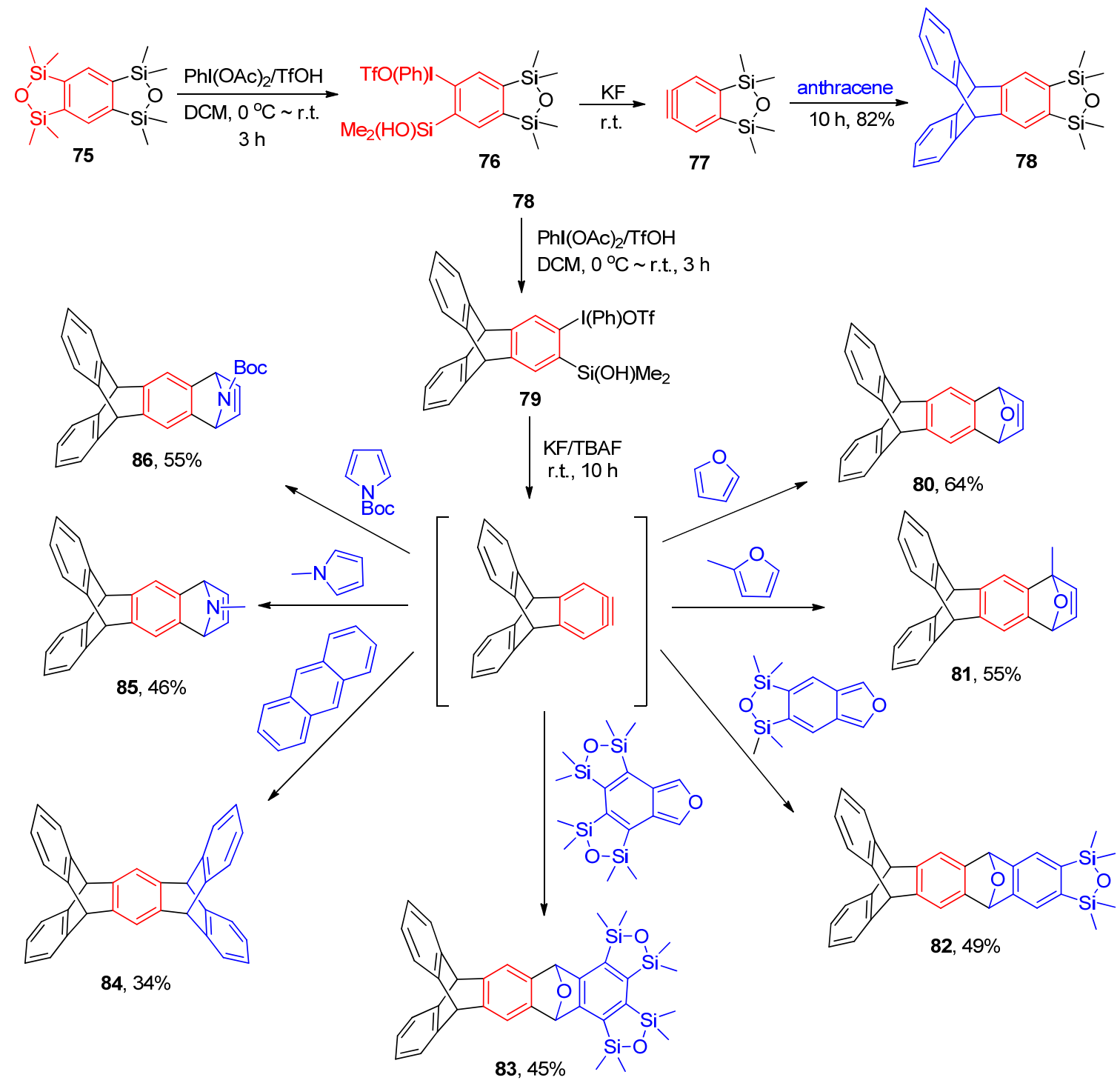

图式 18 苯并噁二硅氧烷生成的苯炔与不同双烯体的 $[4+2]$ 环加成反应

Scheme $18[4+2]$ cycloaddition reaction of dienes with arynes generated from benzooxadisiloles

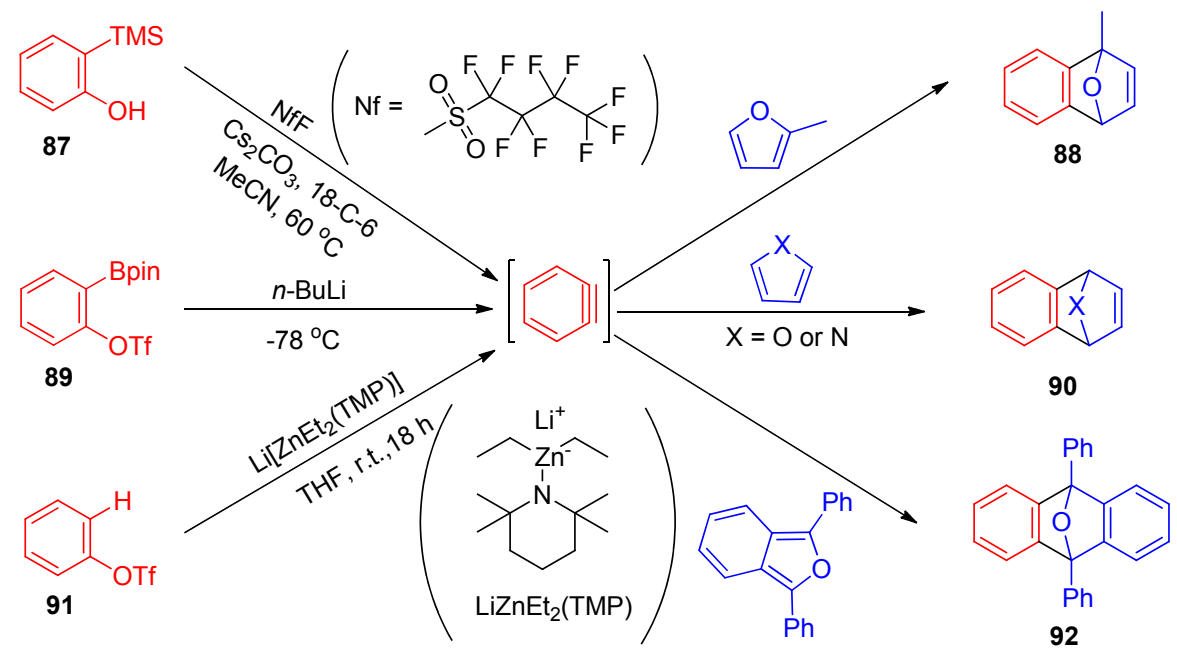

(a)

图式 19 不同苯炔前体与(异苯并)呋喃的[4+2]环加成反应

Scheme 19 [4+2] cycloaddition reaction of various aryne precursors with (isobenzo)furans 

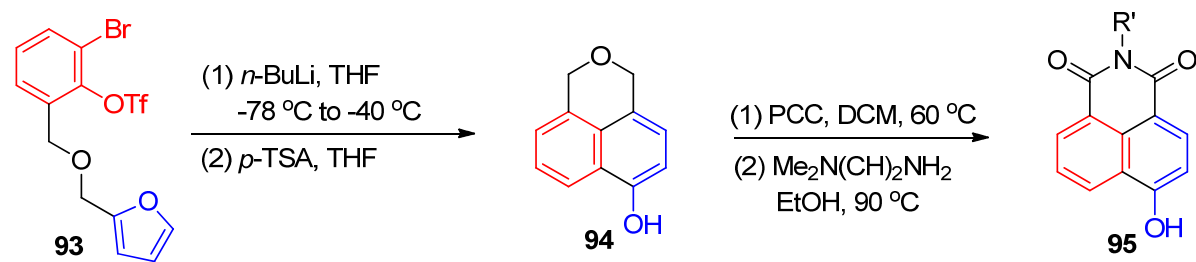

图式 20 苯炔与呋喃的分子内 $[4+2]$ 环加成去芳构化反应

Scheme 20 Intramolecular [4+2] cycloaddition dearomatization reaction of arynes with furan<smiles>Brc1c(Br)c(C#Cc2ccccc2)c2ccccc2c1C#Cc1ccccc1</smiles><smiles>C(#Cc1oc(C#Cc2ccccc2)c2ccccc12)c1ccccc1</smiles>

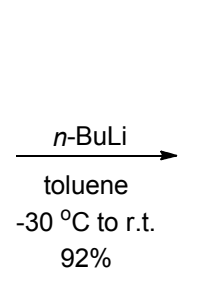

97

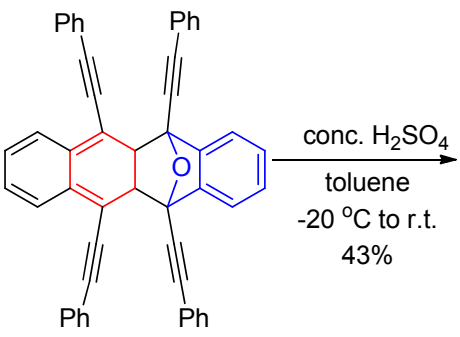

98<smiles>C(#Cc1c(C#Cc2ccccc2)c(C#Cc2ccccc2)c2ccccc2c1C#Cc1ccccc1)c1ccccc1</smiles>

99<smiles>c1ccc(-c2c3ccccc3c(-c3ccccc3)c3c(-c4ccccc4)c4ccccc4c(-c4ccccc4)c23)cc1</smiles>

100<smiles></smiles>

101

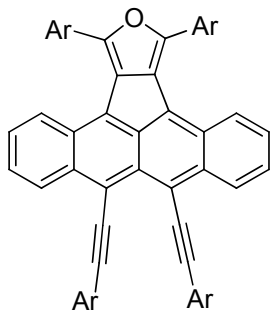

102

图式 21 苯炔与 1,3-二苯乙炔基异苯并呋喃的 [4+2]环加成反应

Scheme $21[4+2]$ cycloaddition reaction of arynes with 1,3-bis(phenylethynyl)isobenzofuran<smiles>Oc1ccc(O[As]c2cccc(Br)c2O)cc1</smiles>

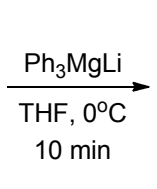

$10 \mathrm{~min}$

103

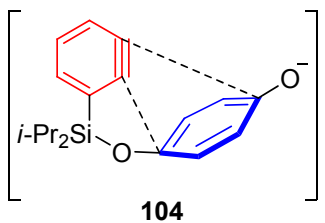

104<smiles></smiles>

图式 22 苯炔与酚盐的分子内 $[4+2]$ 环加成去芳构化反应

Scheme 22 Intramolecular [4+2] cycloaddition dearomatization reaction of arynes with Phenolates

将上述 $[4+2]$ 环加成去芳构化反应用于串联反应中 可构筑更为复杂的分子骨架. 2009 年, Greaney 课题组 ${ }^{[40]}$ 利用两种苯炔前体分别与 $N$-甲基吡咯发生去芳构化反 应后, 可得到 $N$-甲基苯基萗胺 108 或 $N$-甲基二氢吲哚并 荎 111 (Scheme 23). 作者认为, Kobayashi 苯炔前体与 $N$ 甲基吡咯发生 $[4+2]$ 环加成反应生成三氟甲磺酸盐中间 体 107, 其反应体系呈碱性, 促使中间体 107 发生消除 得到 $N$-甲基苯基萗胺 108 . 当使用邻溴氟苯 109 作苯炔 前体时, 其与吡咯发生 $[4+2]$ 环加成反应后, 得到的两 性离子中间体 110 可进一步发生分子内氮杂 Claisen 重 排得到 $N$-甲基二氢吲哚并萗 111 .

2014 年, Biju 课题组 ${ }^{[41]}$ 实现苯炔与苯并呋喃的 $[4+$ $2] /[2+2]$ 一锅法串联反应, 成功构筑了一系列二氢苯并

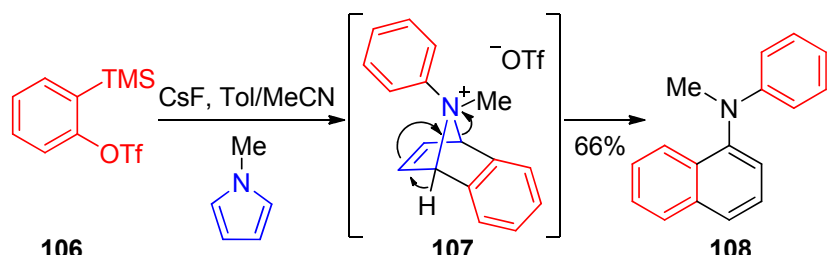

106

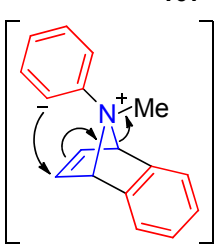

110

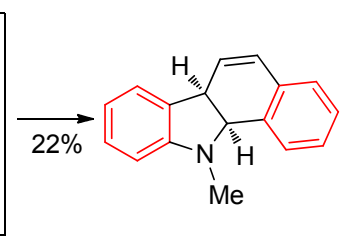

111

图式 23 苯炔与氮甲基吡咯的 [4+2]环加成串联反应 Scheme 23 Tandem [4+2] cycloaddition reaction of arynes with $N$-methylpyrrole 
环丁菲衍生物 114 (Scheme 24, a). 苯并呋喃与苯炔发生 $[4+2]$ 环加成反应得到去芳构化产物 113, 其进而同另 一分子苯炔发生 $[2+2]$ 环加成反应得到目标产物 114. 此外，利用该反应可一锅法合成苂光分子苯并萤葱 117 (Scheme 24, b).

(a)
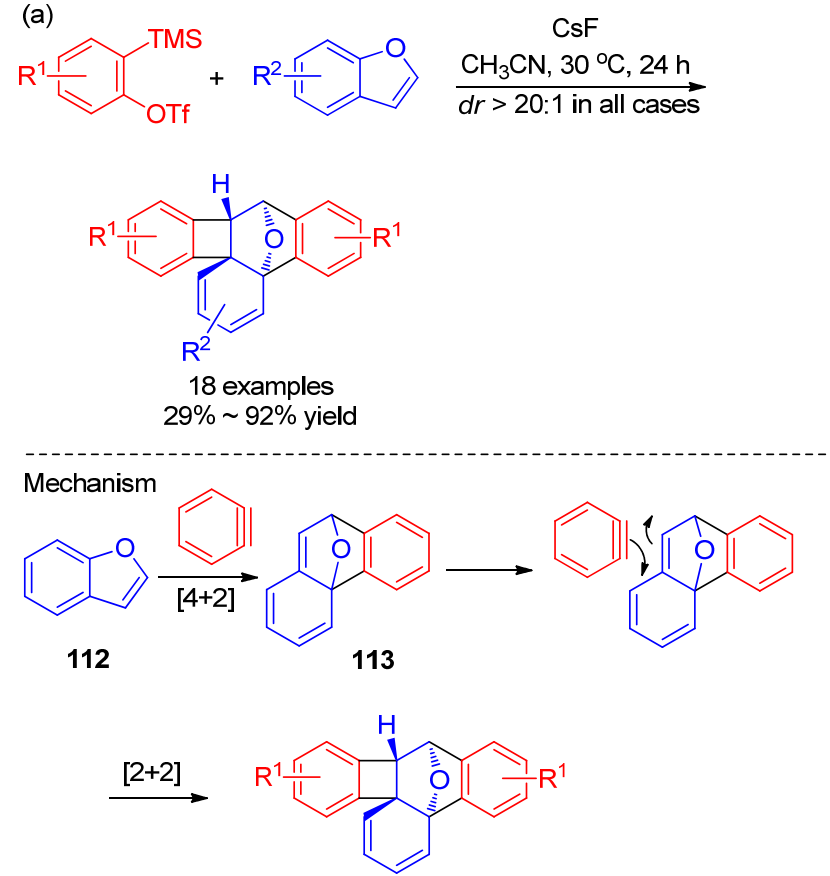

114

(b)

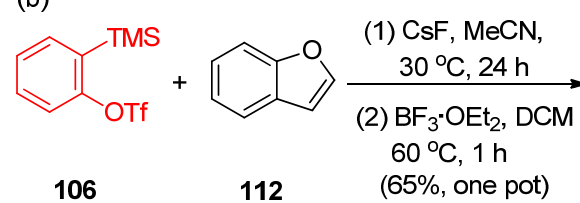
106 112 (65\%, one pot)

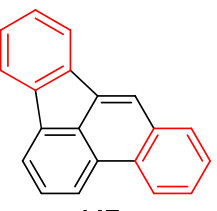

117 tandem $[4+2] /[2+2]$
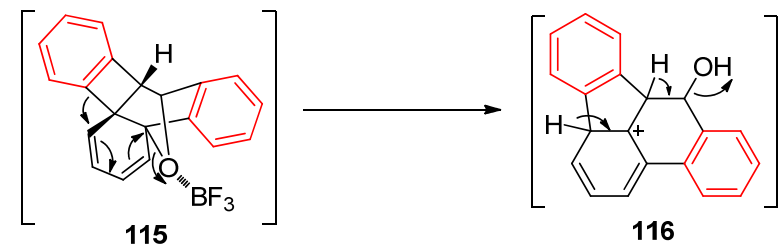

图式 24 苯炔与苯并呋喃的 $[4+2] /[2+2]$ 环加成串联反应 Scheme 24 Tandem $[4+2] /[2+2]$ cycloaddition reaction of arynes with benzofuran

\section{2 天然产物合成中的应用}

苯炔参与的 $[4+2]$ 环加成去芳构化反应, 在天然产 物全合成中也具有广泛应用. 早在 1992 年, Suzuki 等 ${ }^{[42]}$ 便利用此策略实现了天然产物 ent-gilvocarcin $\mathrm{M}$ 的高效 合成. 近年来, 该类反应更是为全合成工作中构筑稠环
分子骨架提供高效路径.

2010 年, Martin 课题组 ${ }^{[43]}$ 报道了 isokidamycin 的全 合成. 二溴苯 118 在正丁基锂作用下原位生成苯炔 $\mathbf{1 1 9}$, 随后与呋喃环发生分子内 $[4+2]$ 环加成反应构建桥环产 物 120. 其在四丁基氟化铵作用下发生硅醚链断裂，进 而同碘甲烷反应便得到中心骨架 121 (Scheme 25).

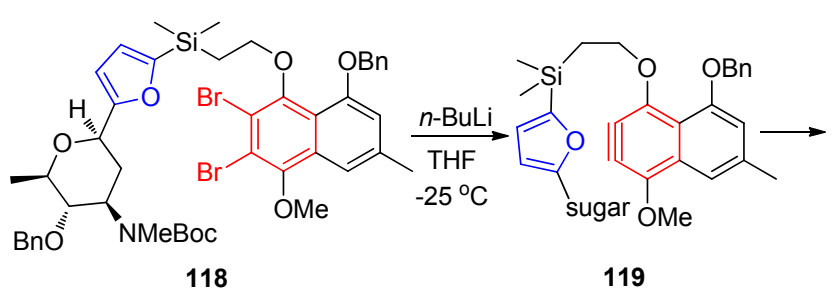

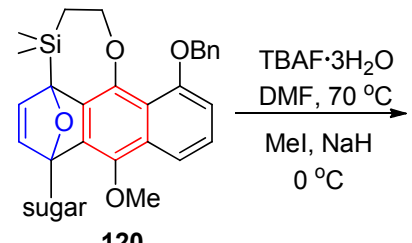

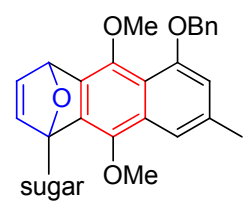

121

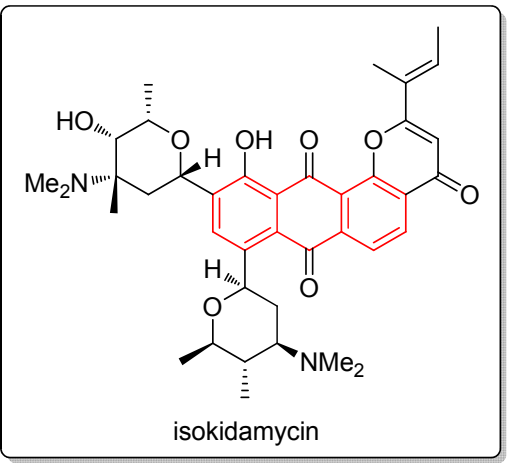

图式 25 苯炔引发的 $[4+2]$ 环加成反应合成 isokidamycin Scheme 25 Aryne induced [4+2] cycloaddition reaction in the synthesis of isokidamycin

2014 年, Hosoya 课题组 ${ }^{[44]}$ 在合成天然产物 defucogilvocarcin $\mathrm{M}$ 的过程中, 利用邻三氟甲磺酸酯基 苯硼酸频哪醇酯 122 为苯炔前体，在仲丁基锂作用下与 2-甲氧基呋喃高效构建萗酚骨架 124 (Scheme 26). 产物 124 中酚差基邻位被嗍酸酯活化后，再与另一分子 2-三 氟甲磺酸酯基苯硼酸酯发生分子间环化反应便可实现 目标天然产物 defucogilvocarcin M 的全合成.

2015 年, Lewis 课题组 ${ }^{[45]}$ 报道 arnottins I 和 II 的全合 成方法(Scheme 27). 作者利用 Kobayashi 苯炔前体 125 与呋喃 126 在氟化铯作用下，通过分子间[4+2]环加成 反应得到氧桥环产物 128 , 再在对甲苯磺酸作用下开环 生成内酯 arnottin I. arnottin I 在碱性条件下水解后, 与 $\mathrm{PhI}\left(\mathrm{O}_{2} \mathrm{CCF}_{3}\right)_{2}$ 作用发生去芳构化得到螺环产物 arnottin II. 
<smiles>Oc1cccc(Br)c1OCCc1ccccc1</smiles>

122

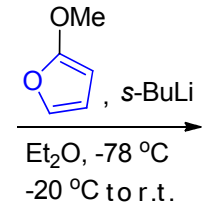<smiles></smiles>

123

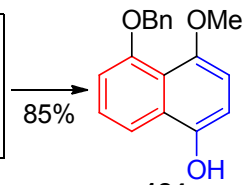

124<smiles>COc1cc(C)cc2c1cc(OC)c1c3cccc(O)c3c(=O)oc21</smiles>

图式 26 苯炔 $[4+2$ ]环加成反应合成 defucogilvocarcin M Scheme 26 Aryne [4+2] cycloaddition reaction in the synthesis of defucogilvocarcin $\mathrm{M}$<smiles>COc1ccc(-c2ccoc2)c(C(=O)OCC(C)(C)C)c1OC</smiles>
125

126<smiles>COC(=O)c1c(-c2cc3oc2c2cc4c(cc32)OCC4)ccc(OC)c1OC</smiles><smiles>COc1ccc(C2=C[C@H]3O[C@@H]2c2cc4c(cc23)OCO4)c(C(=O)O[Na])c1OC</smiles>
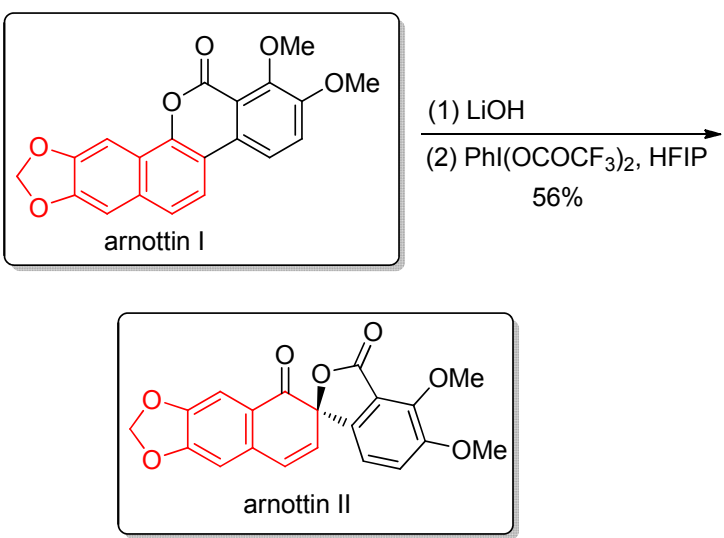

图式 27 苯炔引发的 $[4+2]$ 环加成反应合成 arnottins I 和 II Scheme 27 Aryne induced [4+2] cycloaddition reaction in the synthesis of arnottins I and II

2016 年, MacMillan 课题组 ${ }^{[46]}$ 报道一种 rifsaliniketal 的全合成方法. 作者用间二澳苯 129 同二异丙基氨基锂 发生消除反应生成苯炔, 其再与呋喃反应得到环加成产
物 131, 随后通过氧桥环开环生成荎醌. 最后通过胺化 反应引入侧链完成目标天然产物 rifsaliniketal 的全合成 (Scheme 28).
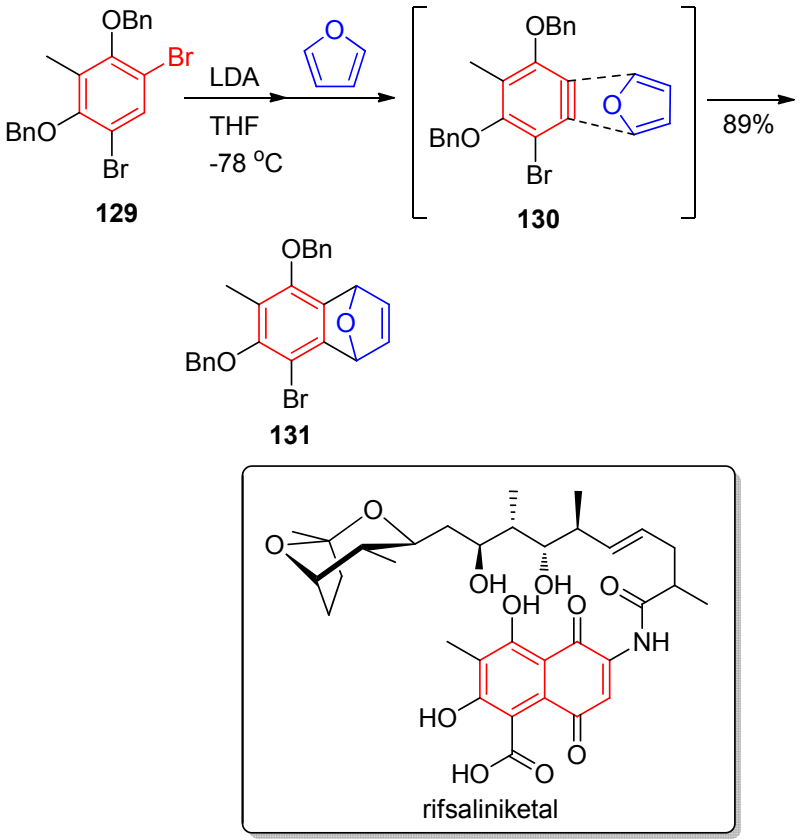

图式 28 苯炔引发的 $[4+2]$ 环加成反应合成 rifsaliniketal Scheme 28 Aryne induced [4+2] cycloaddition reaction in the synthesis of rifsaliniketal

\section{3 其它苯炔参与的去芳构化反应}

除上述案例外，苯炔也可以通过其它独特反应活性 途径参与去芳构化反应. 2018 年, Lee 课题组 ${ }^{[4]}$ 以 HDDA 反应生成苯炔, 利用卡宾中间体介导实现苯环的 去芳构化反应(Scheme 29). 该工作以苯磺酰胺基链状 三炔分子出发，通过去芳构化反应合成一系列五环分子 骨架 140. 密度泛函理论(DFT)计算指出，三炔分子经 HDDA 反应生成的苯炔中间体 $\mathbf{1 3 2}$, 通过环丙基低能过 渡态 133 形成卡宾中间体 134, 再与苯磺酰基亲核加成 生成两性离子中间体 136, 随后经环丙基部分扩环与分 子内异构化得到去芳构化产物 140. 作者提出苯炔与双 键反应所得到的中间体具有双卡宾的性质，因此促进环 丙烷化反应. 此外, 作者认为炔烃链上稳定的阳离子取 代基与苯磺酰基上的缺电子基可促进该反应的进行.

2018 年, 奕新军课题组 ${ }^{[8]}$ 利用钯催化下苯炔和 4酯基-联(2-碘苯基)萗的 $[3+2]$ 螺环去芳构化反应高效合 成一系列螺苆分子(Scheme 30). 其通过钯试剂芳基碘 的氧化加成及后续对苯炔的加成，进而实现去芳构化， 最终得到螺环产物. 作者提出如下反应机理: 碘苯 141 首先和钯发生氧化加成生成中间体 142 , 苯炔随即插入 碳-钯键生成芳基钯中间体 143 . 后续则可能存在两条 反应路径: (I)芳基钯中间体 $\mathbf{1 4 3}$ 直接在碱作用下去质子 

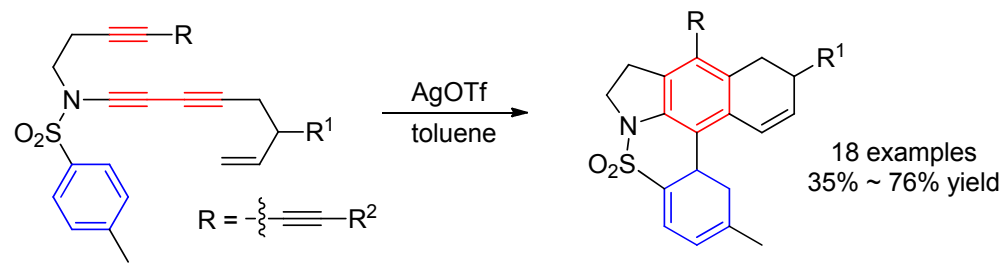

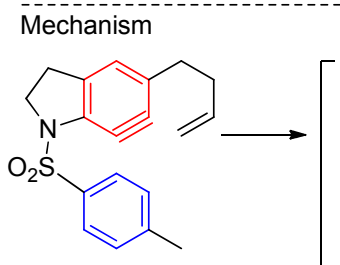

132

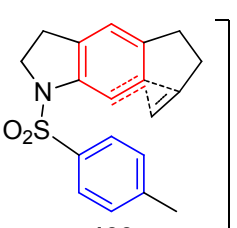

133

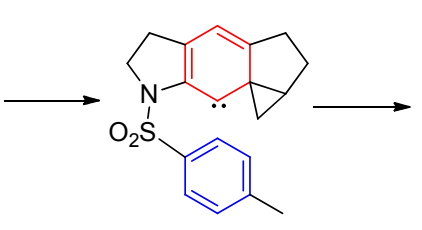

134

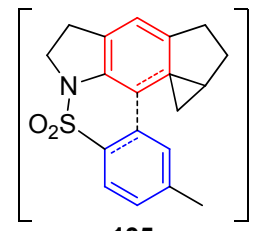

135

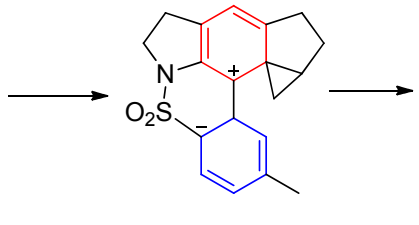

136

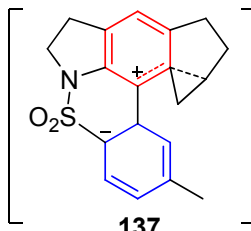

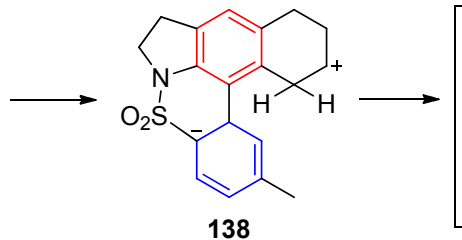

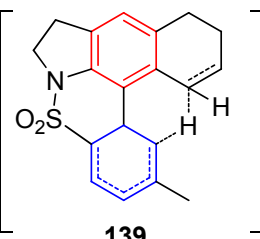<smiles>COC1=CC=C(C)CC1c1c2c(cc3c1N(OC)CC3)CCC=C2</smiles>

图式 29 卡宾介导的苯炔去芳构化反应

Scheme 29 Carbene mediated aryne-based dearomatization reactions

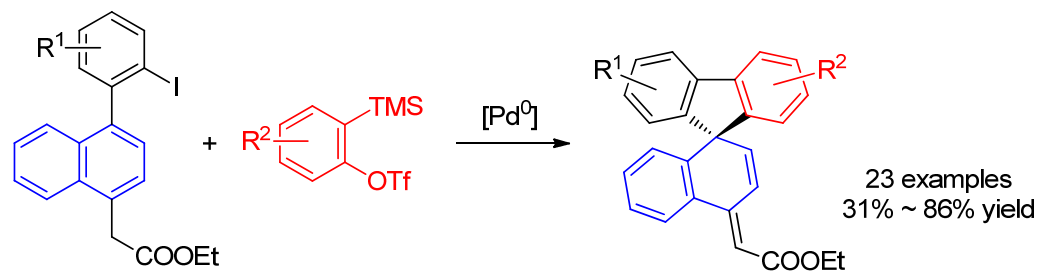

\section{Mechanism}
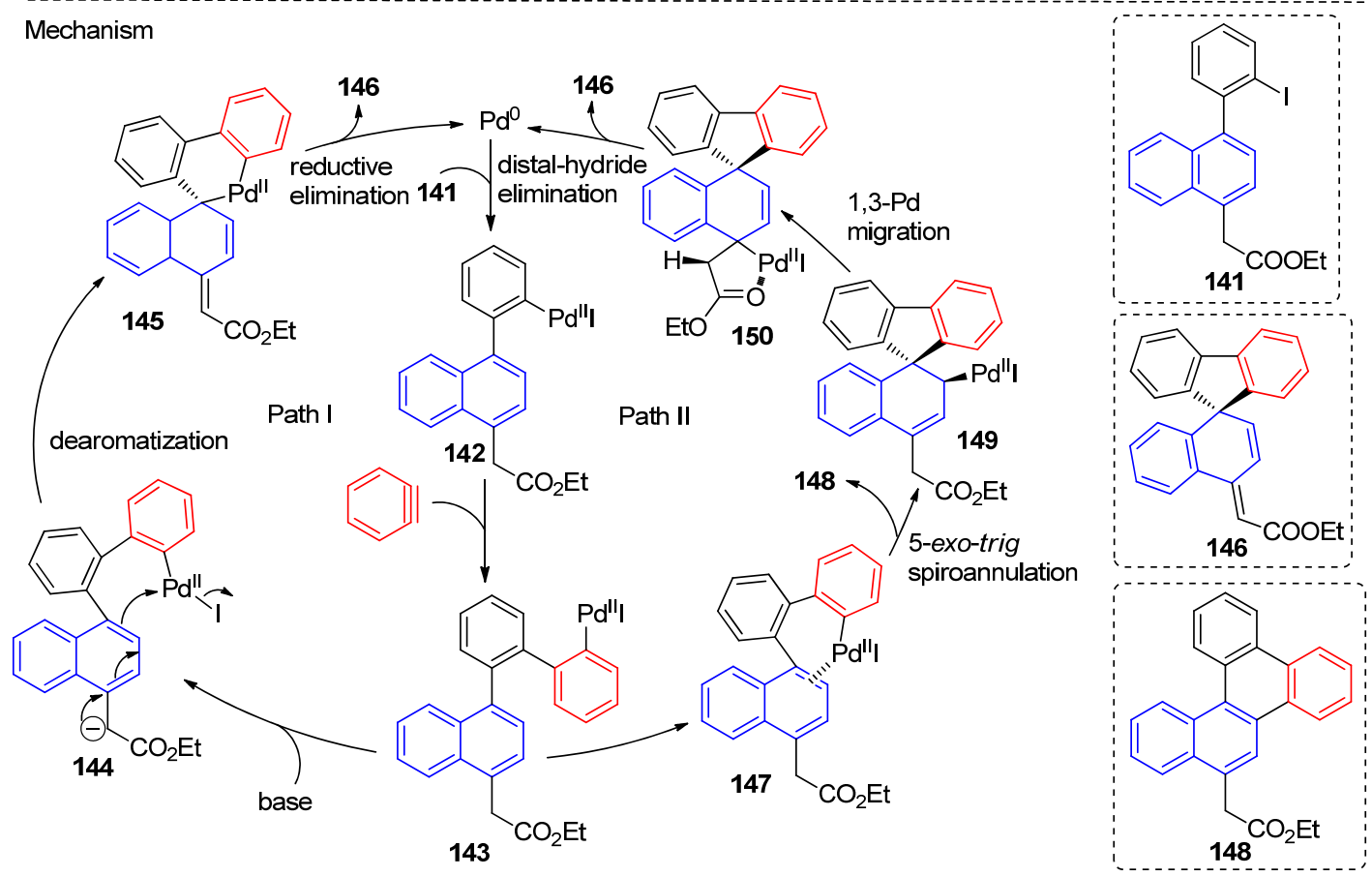

图式 30 钯催化的苯炔插入去芳构化反应

Scheme 30 Palladium-catalyzed dearomative aryne insertion reactions 
化形成环钯中间体 $\mathbf{1 4 5}$, 进而通过还原消除得到目标产 物 146; (II)芳基钯中间体 143 发生 Heck 类型反应，利用 5-exo-trig 螺环化后, 经过 1,3-钯迁移与末端氢消除得到 目标产物 146, 此阶段观察到未去芳构化的稠环产物 148 的生成, 进一步证明苯环碳一氢键可直接被芳基化. 该反应产率较高, 底物适用范围较广, 且为首例过渡金 属催化下苯炔参与的去芳构螺环化反应.

\section{4 总结与展望}

综上所述，苯炔参与的去芳构化反应为合成高官能 才化的三维结构分子提供了一类高效路径. 一方面, 氮 杂芳烃通过同苯炔的亲核加成反应，可引发三组分或两 组分的去芳构化反应，高效合成一系列二氢氮杂芳烃类 化合物; 另一方面, 苯炔可作为亲双烯体与含有 “双烯 骨架” 的芳烃发生经典的 $[4+2]$ 环加成反应, 使双烯体 发生去芳构化，构筑桥环产物.

总而言之, 芳香烃类化合物通过苯炔参与反应发生 去芳构化后, 可增加分子在三维空间结构的多样性, 有 助于高效扩大 “化学空间”。但该类反应的芳环底物较 为单一, HDDA 方法参与的去芳构化反应仍鲜有报道, 且第三组分亲电底物范围较窄. 因此, 探寻更广泛的芳 环底物与捕获两性离子中间体的各类亲电试剂将是该 类反应未来发展的重要方向之一. 苯炔参与去芳构化反 应发展核心依然要强调机理研究, 可考虑将苯炔化学结 合过渡金属催化, 探究新的反应活性. 此外, 发展和建 立同苯炔引发反应条件友好兼容的不对称催化体系以 构筑手性去芳构化产物, 具有重大的研究价值和潜力, 相关研究亟待开展. 坚信随着研究方法的不断深入, 苯 炔参与的去芳构化反应未来会更加高效多样, 在有机合 成中取得更广泛的应用.

\section{References}

[1] Lovering, F.; Bikker, J.; Humblet, C. J. Med. Chem. 2009, 52, 6752.

[2] Lebrasseur, N.; Fan, G.-J.; Oxoby, M.; Looney, M. A.; Quideau, S. Tetrahedron 2005, 61, 1551.

[3] Kohmoto, S.; Masu, H.; Tatsuno, C.; Kishikawa, K.; Yamamoto, M.; Yamaguchi, K. J. Chem. Soc., Perkin Trans. 1 2000, 4464.

[4] Caruana, P. A.; Frontier, A. J. Tetrahedron 2004, 60, 10921.

[5] (a) Zhuo, C. X.; Zhang, W.; You, S. L. Angew. Chem., Int. Ed. 2012, $51,12662$.

(b) Zhu, M.; Zhang, X.; You, S.-L. Chem. J. Chin. Univ. 2020, 41, 1407 (in Chinese).

(朱敏, 张霄, 游书力, 高等学校化学学报, 2020, 41, 1407.)

(c) Wu, W.-T.; Zhang, L.; You, S.-L. Acta Chim. Sinica 2017, 75, 419 (in Chinese). (吴文挺, 张立明, 游书力, 化学学报, 2017, 75, 419.)

[6] (a) Fan, L.-X.; Liu, J.-J.; Bai, L.; Wang, Y.-Y.; Luan, X.-J. Angew. Chem., Int. Ed. 2017, 56, 14257.

(b) Bai, L.; Liu, J.-J.; Hu, W.-J.; Li, K.-Y.; Wang, Y.-Y.; Luan, X.-J. Angew. Chem., Int. Ed. 2018, 57, 5151. (c) Nan, J.; Yuan, Y.-N.; Bai, L.; Liu, J.-J.; Luan, X.-J. Org. Lett. 2018, 20, 7731.

(d) Hu, W.-J.; Wang, H.; Bai, L.; Liu, J.-J.; Luan, X.-J. Org. Lett. 2018, 20, 880 .

(e) Tan, B.-J.; Bai, L.; Ding, P.; Liu, J.-J.; Wang, Y.-Y.; Luan, X.-J. Angew. Chem., Int. Ed. 2019, 58, 1474.

[7] Jeganmohan, M.; Cheng, C.-H. Chem. Commun. 2006, 2454.

[8] Jeganmohan, M.; Bhuvaneswari, S.; Cheng, C.-H. Chem.-Asian J. 2010, $5,153$.

[9] Nakano, H.; Tsugawa, R.; Fujita, R. Tetrahedron Lett. 2005, 46, 5677.

[10] Liu, K.; Liu, L.-L.; Gu, C.-Z.; Dai, B.; He, L. RSC Adv. 2016, 6, 33606.

[11] Tan, J.-J.; Liu, B.-B.; Su, S.-S. Org. Chem. Front. 2018, 5, 3093.

[12] Bhunia, A.; Roy, T.; Pachfule, P.; Rajamohanan, P. R.; Biju, A. T. Angew. Chem., Int. Ed. 2013, 52, 10040.

[13] Bhunia, A.; Porwal, D.; Gonnade, R. G.; Biju, A. T. Org. Lett. 2013, $15,4620$.

[14] Liu, P.; Lei, M.; Hu, L. Tetrahedron 2013, 69, 10405.

[15] Li, S.-J.; Wang, Y.; Xu, J.-K.; Xie, D.; Tian, S.-K.; Yu, Z.-X. Org. Lett. 2018, 20, 4545.

[16] Rayabarapu, D. K.; Majumdar, K. K.; Sambaiah, T.; Cheng, C. H. J. Org. Chem. 2001, 66, 3646.

[17] Rogness, D. C.; Markina, N. A.; Waldo, J. P.; Larock, R. C. J. Org. Chem. 2012, 77, 2743.

[18] Cheng, B.; Wei, J.; Zu, B.; Zhao, J.-F.; Wang, T.-M.; Duan, X.-G.; Wang, R.-Q.; Li, Y.; Zhai, H.-B. J. Org. Chem. 2017, 82, 9410.

[19] Hoye, T. R.; Baire, B.; Niu, D.; Willoughby, P. H.; Woods, B. P. Nature 2012, 490, 208.

[20] Arora, S.; Zhang, J.; Pogula, V.; Hoye, T. R. Chem. Sci. 2019, 10, 9069.

[21] Yamashita, Y.; Hayashi, T.; Masumura, M. Chem. Lett. 1980, 1133.

[22] Zhao, J.; Wu, C.; Li, P.; Ai, W.; Chen, H.; Wang, C.; Larock, R. C.; Shi, F. J. Org. Chem. 2011, 76, 6837.

[23] Huang, X.; Zhang, T. Tetrahedron Lett. 2008, 50, 208.

[24] Xie, C.-S.; Zhang, Y.-H.; Xu, P.-X. Synlett 2008, 20, 3115.

[25] Okuma, K.; Hirano, K.; Shioga, C.; Nagahora, N.; Shioji, K. Bull. Chem. Soc. Jpn. 2013, 86, 615.

[26] Wittig, G. Org. Synth. 1959, 39, 75.

[27] (a) Giles, R. G. F.; Roos, G. H. P. J. Chem. Soc., Chem. Commun. 1975, 260

(b) Hillard, R. L. III; Vollhardt, K. P. C. J. Am. Chem. Soc. 1976, 98, 3579.

(c) Smith, W. B. J. Phys. Org. Chem. 2005, 18, 477.

[28] Himeshima, Y.; Sonoda, T.; Kobayashi, H. Chem. Lett. 1983, 1211.

[29] Chen, Y.-L.; Zhang, H.-K.; Wong, W.-Y.; Lee, A. W. M. Tetrahedron Lett. 2002, 43, 2259.

[30] Chen, Y.-L.; Sun, J.-Q.; Wei, X.; Wong, W.-Y.; Lee, A. W. M. J. Org. Chem. 2004, 69, 7190.

[31] Chen, Y.-L.; Hau, C.-K.; Wang, H.; He, H.; Wong, M.-S.; Lee, A. W. M. J. Org. Chem. 2006, 71, 3512.

[32] Pei, B.-J.; Chan, W.-H.; Lee, A. W. M. J. Org. Chem. 2010, 75, 7332.

[33] Ikawa, T.; Nishiyama, T.; Nosaki, T.; Takagi, A.; Akai, S. Org. Lett. 2011, 13, 1730.

[34] Ikawa, T.; Sun, J.; Takagi, A.; Akai, S. J. Org. Chem. 2020, 85, 3383.

[35] Sumida, Y.; Kato, T.; Hosoya, T. Org. Lett. 2013, 15, 2806.

[36] Cho, S.; Wang, Q. Tetrahedron 2018, 74, 3325.

[37] Prévost, S.; Dezaire, A.; Escargueil, A. J. Org. Chem. 2018, 83, 4871.

[38] Kitamura, K.; Asahina, K.; Nagai, Y.; Sugiyama, H.; Uekusa, H.; 
Hamura, T. Chem.-Eur. J. 2018, 24, 14034.

[39] Takikawa, H.; Nishii, A.; Takiguchi, H.; Yagishita, H.; Tanaka, M.; Hirano, K.; Uchiyama, M.; Ohnori, K.; Suzuki, K. Angew. Chem., Int. Ed. 2020, 59, 12440.

[40] Cant, A. A.; Bertrand, G. H. V.; Henderson, J. L.; Roberts, L.; Greaney, M. F. Angew. Chem., Int. Ed. 2009, 48, 5199.

[41] Bhojgude, S. S.; Thangaraj, M.; Suresh, E.; Biju, A. T. Org. Lett. 2014, 16, 3576 .

[42] Matsumoto, T.; Hosoya, T.; Suzuki, K. J. Am. Chem. Soc. 1992, 114,3568 .

[43] O’Keefe, B. M.; Mans, D. M.; Kaelin, D. E., Jr; Martin, S. F. J. Am.
Chem. Soc. 2010, 132, 15528.

[44] Sumida, Y.; Harada, R.; Kato-Sumida, T.; Johmoto, K.; Uekusa, H.; Hosoya, T. Org. Lett. 2014, 16, 6240.

[45] Moschitto, M. J.; Anthony, D. R.; Lewis, C. A. J. Org. Chem. 2015, $80,3339$.

[46] Feng, Y.; Liu, J.; Carrasco, Y. P.; MacMillan, J. B.; DeBrabander, J. K. J. Am. Chem. Soc. 2016, 138, 7130.

[47] Karmakar, R.; Le, A.; Xie, P.-P.; Xia, Y.-Z.; Lee, D. Org. Lett. 2018, $20,4168$.

[48] Zuo, Z.-J.; Wang, H.; Diao, Y.-X.; Ge, Y.-C.; Liu, J.-J.; Luan, X.-J. ACS Catal. 2018, 8, 11029. 